\title{
Pérdida de humedales y vegetación por urbanización en la cuenca del río Grijalva, México
}

\author{
Loss of wetlands and timberline due to urban sprawl \\ in the basin of the Grijalva River, Mexico
}

\author{
Miguel Ángel Palomeque de la Cruz ${ }^{1}$ \\ Adalberto Galindo Alcántara² \\ Alberto J. Sánchez ${ }^{3}$ (1D \\ Miguel Jorge Escalona Maurice $\mathbb{4}^{\mathbb{D}}$
}

\section{Resumen}

La periurbanización se ha considerado como motor del cambio de uso del suelo y de la pérdida de ecosistemas y de biodiversidad. A partir de esta premisa, la investigación plantea el seguimiento, desde una doble perspectiva, histórica y predictiva, de los cambios en la superficie de los humedales y en la deforestación progresiva entorno a Villahermosa, la urbe más importante de la cuenca del río Grijalva, en el Estado de Tabasco (México). Se han utilizado diferentes métodos: el análisis bibliográfico para el periodo desde la fundación de la ciudad hasta el último tercio del siglo XX, la verificación de fotografías aéreas entre 1984 y 2008 y la modelización de escenarios futuros, entre 2020 y 2040. Desde el periodo colonial hasta mediados del siglo veinte, las inundaciones y la insalubridad dificultaron el crecimiento de la ciudad pese a la transformación de la red hídrica superficial en la cuenca, iniciada mediante la construcción de diques en el siglo XVII. Posteriormente, las elevadas tasas de pérdida de humedales y deforestación $(-0.50$ y $-4.63 \%)$ se incrementaron por la urbanización y el impacto de los programas de producción agropecuaria y petrolización. En los últimos 40 años, el desarrollo periurbano ocasionó la pérdida de 4.008 ha de vegetación arbórea y 289 ha de humedales, con una tendencia a desaparecer 1.449 y 356 ha adicionales respectivamente en el futuro 2040. Estos resultados resaltan la necesidad de rediseñar un programa metropolitano, transdisciplinario y sustentable que respete y actualice las reservas territoriales para regular la periurbanización.

Palabras clave: periurbanización; expansión urbana; uso de suelo; inundaciones; sustentabilidad.

\begin{abstract}
Peri-urbanization has been considered to be the driving force of change in land use and the loss of ecosystems and their biodiversity. In view of this premise, the research provides for the follow up, from a double perspective, historical and predictive, on changes in the area of the wetlands and progressive deforestation in Villahermosa, the most important city in the Grijalva River basin, in the State of Tabasco

\footnotetext{
1 Programa de Doctorado en Ciencias en Ecología y Manejo de Sistemas Tropicales. DACBiol. Universidad Juárez Autónoma de Tabasco, Villahermosa, México. migueldacbiol@hotmail.com

2 DACBiol. Universidad Juárez Autónoma de Tabasco, Villahermosa, México. aga2003a@hotmail.com

3 DACBiol. Universidad Juárez Autónoma de Tabasco, Villahermosa, México. alberthoj.sanchez@gmail.com. Autor de correspondencia.

4 Colegio de Postgraduados Campus Montecillo, Texcoco, México. mescalona@colpos.mx
} 
(Mexico). Different methods have been used: the bibliographic analysis for the period since the founding of the city until the last third of the twentieth century, the verification of aerial photographs between 1984 and 2008, and the modelling of future scenarios between 2020 and 2040. Since the Colonial period until the mid-nineteenth century, floods and unhealthy conditions limited the growth of the city despite the transformation of the surface water drainage to basin scale, which was started through the construction of levees in the seventeenth century. Subsequently, high rates of wetland loss and deforestation $(-0.50$ and $-4.63 \%$ ) increased due to the urbanization and the impact of agricultural production and petroleum programs. In the last 40 years, the fringe development has resulted in the loss of 4,008 ha of timberline vegetation and 289 ha of wetlands, with perhaps an additional 1,449 and 356 ha disappearing by 2040 . These results highlight the need to redesign a metropolitan, transdisciplinary and sustainable program that respect and update the land reserves to regulate the urban sprawl.

Keywords: fringe urbanization; urban sprawl; land use; floods; sustainability.

\section{Introducción}

El crecimiento urbano es un tema relevante en la actual agenda ambiental mundial (Bekessy et al., 2012; da Silva y Cardozo, 2015) por ser uno de los procesos socioambientales dominantes en la transformación de los ecosistemas mediante el cambio de uso del suelo, reducción de los niveles de agua en las zonas de recarga y acuíferos, pérdida de hábitat y disminución de la biodiversidad, deforestación, erosión e improductividad de los suelos (Angeoletto et al., 2015; Hettiarachchi et al., 2014). En este contexto, las ciudades importan y transforman energía del medio ambiente y usan al medio natural como soporte físico y depósito de residuos (Ibarra, Puente y Schteingart, 1984). Las formas que asume la modificación de los ecosistemas por el medio construido, depende de las características físicas y sociales de los espacios circundantes, el ritmo de la expansión urbana, las formas de producción, y el contexto sociopolítico en que suceden estos procesos (Schteingart, 1987). En este sentido, sus consecuencias son especialmente notables en las zonas marginadas de bajo precio y sin servicios municipales, en poblados dedicados a la economía de subsistencia y en ecosistemas conservados y mínimamente habitados ubicadas en la periferia de las ciudades (Bekessy et al., 2012; Carranza y Ruiz, 2012).

En la mayor parte de América Latina, la metropolización de las ciudades se incrementó durante los años noventa del siglo pasado, debido al crecimiento demográfico local (Gutman, 1993). En la primera década del siglo XXI, México fue considerado un país con alto grado de urbanización; por ejemplo en 2005, el 83\% de la población urbana nacional estaba concentrada en 57 zonas metropolitanas (Garza, 2010). El crecimiento urbano en el centro y norte del país ha sido influido tanto por estímulos macroeconómicos, como por la industrialización. En cambio, el turismo y la petrolización promovieron el crecimiento en muchas ciudades costeras en el sur del país (Garza, 2010). En la cuenca baja del río Grijalva, localizada en el sur del país, el crecimiento de la ciudad de Villahermosa, en el estado de Tabasco, se puede relacionar con la centralización de las actividades económicas y con la mayor inserción del territorio en la economía nacional, financiada a través de programas agropecuarios, desarrollo de infraestructuras de comunicaciones terrestres y la petrolización (Allub y Michel, 1979; Capdepont-Ballina y Marín-Olán, 2014; Flores-Santiago, 1987; Gracia y Fuentes, 2004; Murillo y Martínez, 2010; Navarro y Toledo, 2008; Pinkus-Rendón y Contreras-Sánchez, 2012; Sánchez et al., 2015). En 1978 durante el inicio del boom petrolero, tres cuartas partes del PIB total de la economía tabasqueña provenía sólo de la producción de hidrocarburos (Lezama, 1987).

La expansión urbana en México se relacionó con una tasa anual de deforestación de -0,08\% para bosques y -0,41\% para selvas durante 1976-2007 (Rosete-Vergés et al., 2014). De forma simular, la Organización de las Naciones Unidas para la Alimentación y la Agricultura [FAO] (2015) estableció la cifra de $-0.3 \%$ de deforestación de bosques templados y tropicales entre 1990-2015. En las cuencas de los ríos Grijalva y Usumacinta, el área de las selvas se redujo del 36\% al 9 \% de 1993 a 2007 (Kolb y Galicia, 2012). Esta pérdida de masas forestales ha afectado negativamente a la calidad del agua, la biodiversidad y la captura de carbono (Merlín-Uribe et al., 2013). Los humedales perdieron el 62\% de la cobertura nacional durante 2002-2008, y más de la mitad de los Estados que tienen superficies de humedales, han perdido el $50 \%$ de éstos. La cuenca baja del río Grijalva, localizada en el estado de Tabasco, fue la que más humedales perdió en México (Landgrave y Moreno-Casasola, 2012). El cambio de uso del suelo en esta 
zona se ha relacionado con el relieve y la pendiente, el crecimiento poblacional, la expansión ganadera, la explotación forestal, la implementación de proyectos agropecuarios, el aprovechamiento petrolero y el crecimiento de la ciudades (Capdepont-Ballina y Marín-Olán, 2014; Perevochtchikova y Lezama, 2010).

En esta región, la periurbanización de Villahermosa produjo la modificación de la fisiografía de su territorio, ya que proliferó la práctica de fragmentar los humedales y rellenar sus áreas de inundación temporal, a lo que se añadió la deforestación y transformación de la red fluvial superficial de los ríos de la cuenca Grijalva (Kolb y Galicia, 2012; Navarro y Toledo, 2008; Zavala y Castillo, 2007; Sánchez et al., 2015). Esta modificación de la red fluvial superficial de la cuenca Grijalva destaca debido a que, sumado su flujo al de la cuenca del río Usumacinta, ambas son la principal reserva de agua de México (Sánchez et al., 2015), y es donde se registra la máxima biodiversidad de peces del país (Miller et al., 2005). Además, la suma de intervenciones y modificaciones en los ecosistemas de la ciudad y de la cuenca intensificaron la vulnerabilidad de sus habitantes, como pudo comprobarse en la inundación extrema de octubre de 2007 cuando fueron afectadas 50.561 viviendas y el 75\% de la población fue damnificada con pérdidas que ascendieron a 3.100 millones de dólares en el conjunto de la cuenca baja del Grijalva (Comisión Económica para América Latina y el Caribe [CEPAL], 2008). A pesar de la enseñanza histórica ambiental de las inundaciones, la ciudad ha seguido creciendo con las mismas prácticas de un desarrollo periurbano caracterizado por omitir la conservación de las funciones, servicios y beneficios de los humedales.

\section{1. Área de estudio}

La ciudad de Villahermosa, en la ribera del río Grijalva, (figura 1) fue nombrada oficialmente como tal en 1916 (Torruco, 2014), pero su fundación se remonta al al 24 de junio de 1564 con la denominación de Villa San Juan Bautista (figura 2). Los antecedentes de su establecimiento se encuentran en el posclásico en la desembocadura de los ríos Grijalva-Usumacinta, ya que Potonchán fue un importante puerto fluvial y marino maya que fue invadido por Cortés en 1519 (Chávez-Jiménez 2007). En 1525, en Potonchan se fundó la Villa de Santa María de la Victoria con la intención de continuar el comercio marítimo y se convirtió en la capital de la provincia de Tabasco. Pero desde 1570 hubo registros de incursiones piratas, que aumentaron en 1957 provocando la migración río arriba de algunos pobladores a Villa Carmona, nombrada después San Juan Bautista (Chávez-Jiménez, 2007). Además, en 1597 los piratas invadieron y quemaron Santa María de la Victoria, también llegaron a atacar en San Juan Bautista, por lo cual los poderes se trasladaron a la zona montañosa en Tacotalpa (Chávez-Jiménez, 2007; Ruiz-Abreu, 2002; Ruz, 2002; Salazar-Ledesma, 2000). En 1641 se oficializó el traslado de la capital de la Provincia de Tabasco a San Juan Bautista, aunque la misma no se mantuvo constante en el tiempo, pues las invasiones piratas, las alianzas de los nativos con los piratas y la migración hacia la provincia de Chiapas causaron inestabilidad social y económica en toda la provincia (Ruiz-Abreu, 2002; Ruz, 2002; Chávez-Jiménez, 2007; Salazar-Ledesma, 2000; 2002). No fue hasta 1795, cuando la administración virreinal regresó a San Juan Bautista, ya que esta Villa fue declarada puerto menor tres años antes, lo que ayudó a concentrar las actividades comerciales, políticas, sociales y culturales (Ruiz-Abreu, 2002; Torruco, 2014).

En las cuencas de los ríos Grijalva y Usumacinta se registraron las mayores reservas potenciales de agua en México (Comisión Nacional del Agua [CONAGUA], 2011) y en la porción baja de la cuenca del río Grijalva se ubica la ciudad de Villahermosa, que es su asentamiento humano más importante (figura 1). Villahermosa tiene un área actual de 20.655 ha (Instituto de Planeación y Desarrollo Urbano del Municipio de Centro [IMPLAN], 2008). En 2016, 419.000 habitantes se registraron y su actividad económica entre 2013, 2014 y 2015, generó ingresos de más de seis mil millones de pesos, aportando el $24.68 \%$ de la renta estatal (Heroico Ayuntamiento del Municipio de Centro 2016-2018, 2016). En Villahermosa existen aún 13 ecosistemas lagunares fluviales y de contacto relacionados con las redes hidráulicas de los ríos Mezcalapa Viejo, Carrizal y Sierra-Grijalva que rodean la zona urbana (figura 3). La ciudad resulta de importancia nacional por ser la capital del estado de Tabasco y por su actividad económica basada con anterioridad en la producción agropecuaria y en las últimas décadas en la extracción de hidrocarburos (Allub y Michel, 1979; Capdepont-Ballina y Marín-Olán, 2014). Esta última actividad económica influyó en el crecimiento acelerado de la población y de su metropolización desde finales del siglo pasado (Capdepont-Ballina y Marín-Olán, 2014; Cerna, de la Peña, Antonio y Reyna y Díaz, 2011). 
Figura 1. Mapa de la ciudad de Villahermosa en la cuenca baja del río Grijalva, México

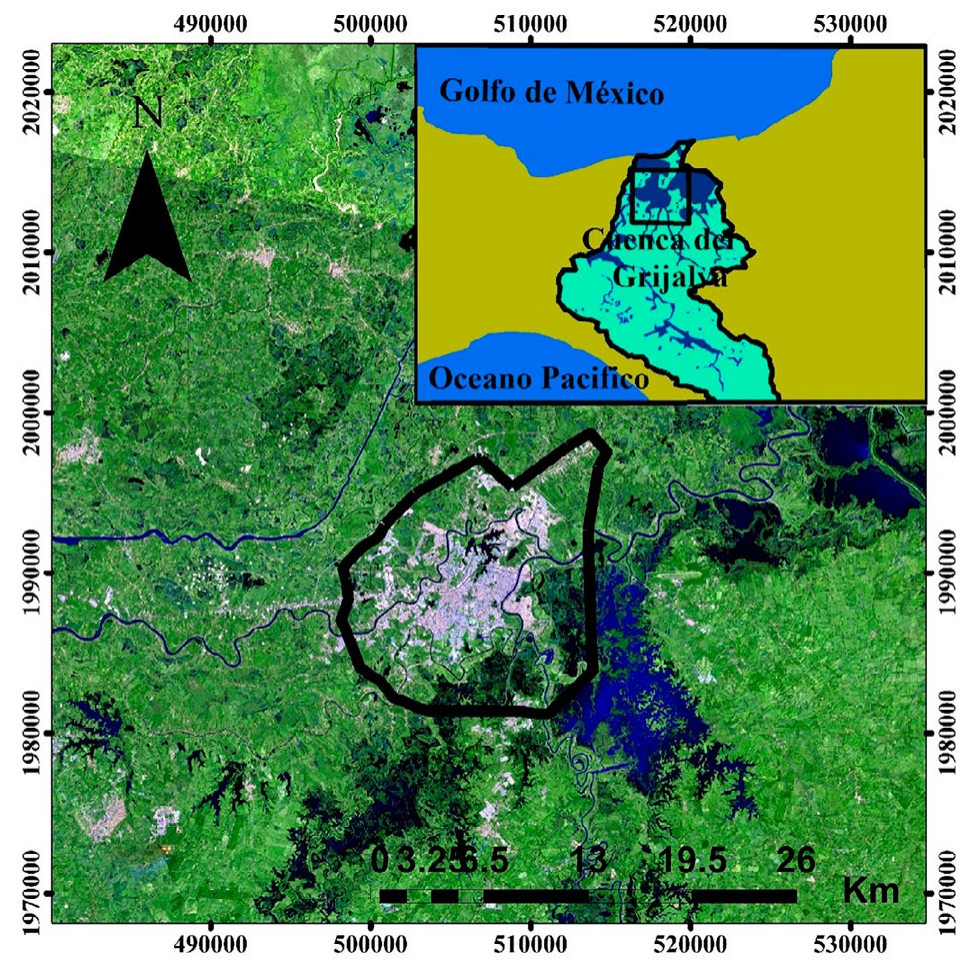

Fuente: imagen LANDSAT de 2015 (la zona Metropolitana está delimitada mediante una línea negra). Elaboración propia.

Figura 2. San Juan Bautista: (a) sus humedales en 1884, (b) sus poblados Atasta-Tamulté y el sistema hidrológico

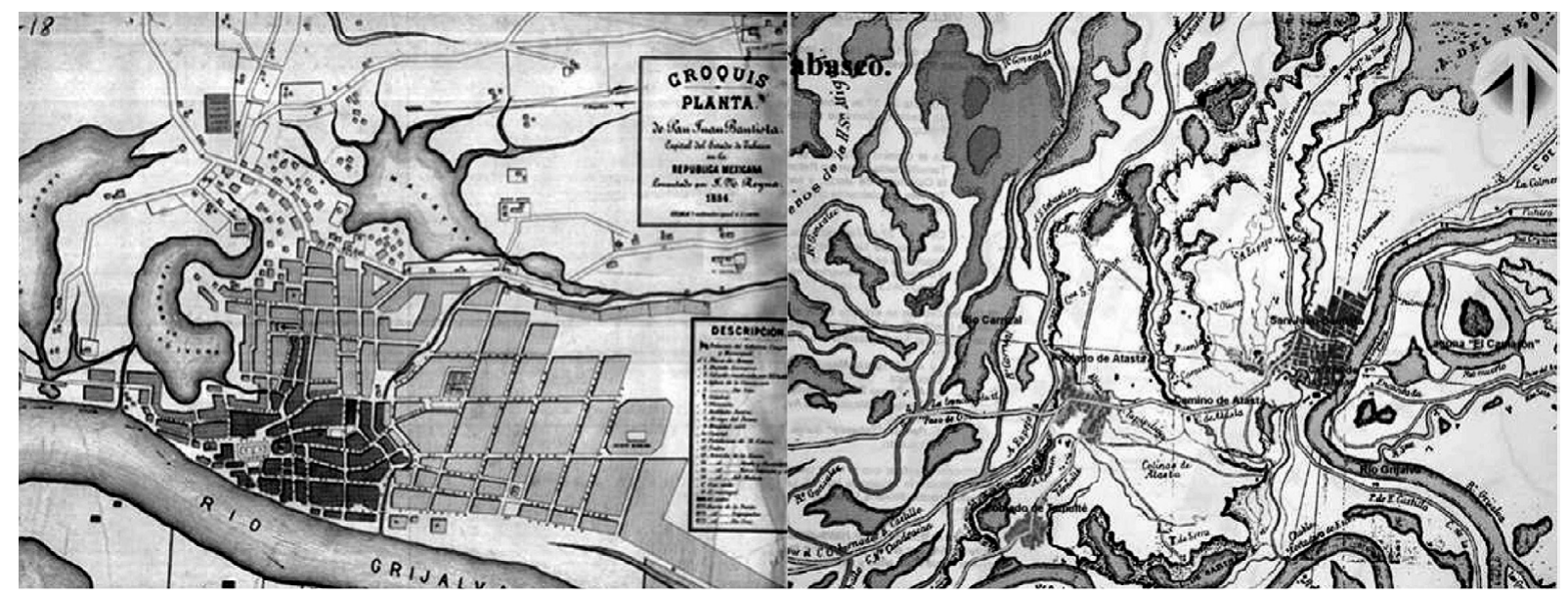

Fuente: Gurría-Lacroix et al., 1982.

\subsection{Objetivos}

En este ámbito donde la periurbanización, acompañada de modificaciones en la fisiografía de su territorio en diferentes escalas espaciales y temporales ha sido un fenómeno secular, la relación entre el territorio y las respuestas que durante el tiempo cada sociedad ha dado ante su crecimiento y las variaciones naturales del ambiente (Bekessy et al., 2012; Schteingart, 1987) ayudan a explicar los procesos de urbanización y sus impactos ambientales. Sin embargo, en Villahermosa existen pocos análisis sobre el estado actual y tendencias de cambio de los usos del suelo por urbanización, a pesar de ser información indispensable para sustentar la planificación ambiental dirigida a restablecer servicios y beneficios 
ambientales que se traduzcan en bienestar social. En consecuencia, el objetivo de analizar los hechos históricos más relevantes en la sustitución de vegetación arbórea y humedales por zonas urbanas y periurbanas en la ciudad de Villahermosa, así como los efectos de las políticas que han privilegiado el desarrollo económico y la protección contra inundaciones de esta urbe, mostrarán que la expansión urbana ha alterado las funciones y los servicios ambientales en la metrópoli y en la cuenca del río Grijalva en donde Villahermosa está asentada. Además, el estudio integrado sumado al análisis de cambio de usos de suelo y proyecciones de sus escenarios, aportarán información relevante para ser sopesada en el rediseño de un programa de urbanización.

Figura 3. Paisaje urbano, ríos y pantanos en Villahermosa

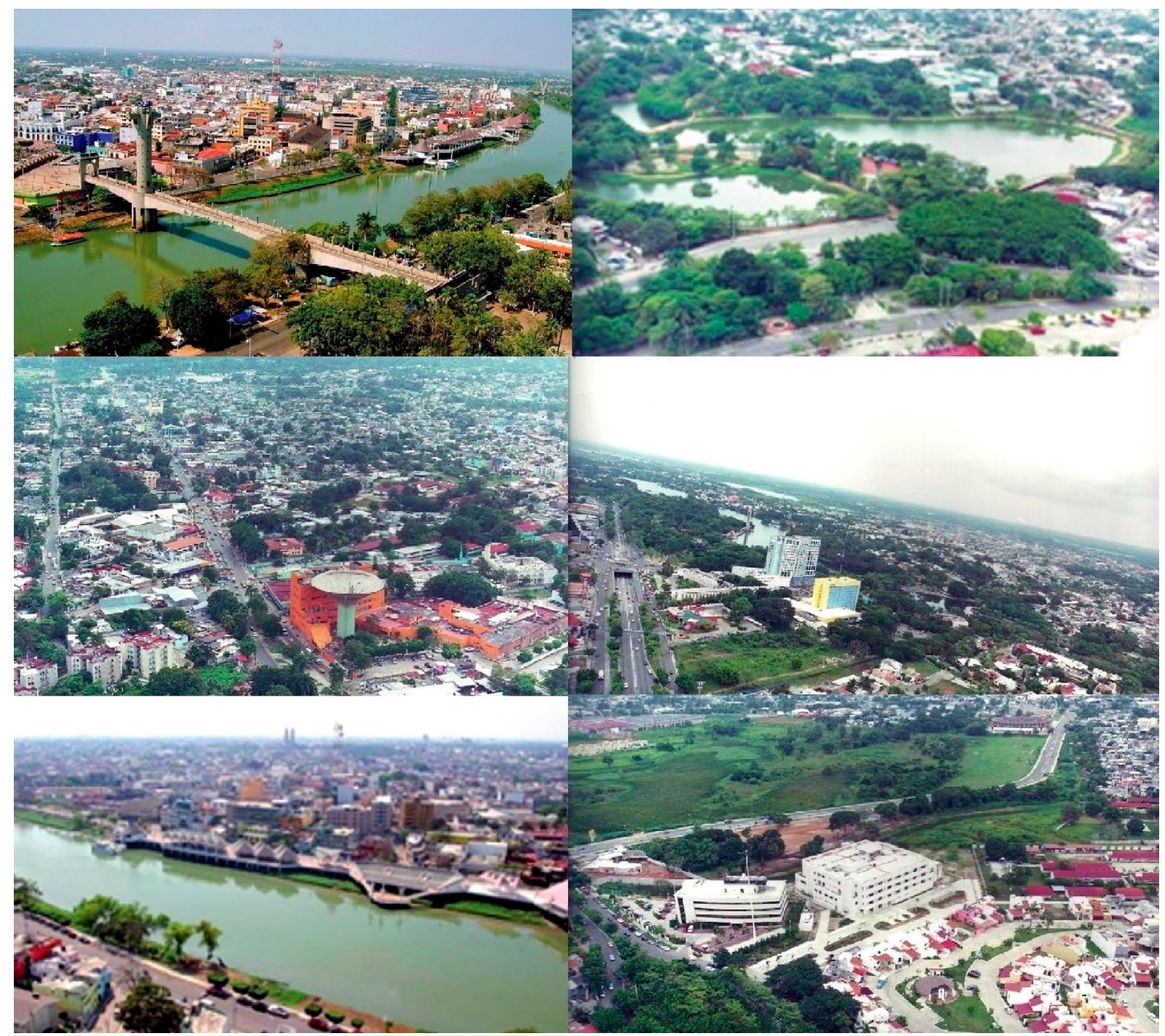

Fuente: Cerna et al., 2011.

\section{Metodología}

La descripción de los hechos históricos más relevantes del crecimiento urbano de Villahermosa relacionados con las modificaciones de sus ecosistemas más representativos en la cuenca baja del río Grijalva se inició con el análisis de fuentes recopiladas que incluyeron desde de las primeras modificaciones registradas en la red fluvial superficial con los primeros asentamientos urbanos en la cuenca, desde la época colonial hasta el segundo tercio del siglo XX. Posteriormente, los cambios de uso de suelo de los periodos 1984 - 2008 y 2020 - 2040 se modelizaron en relación con la expansión urbana y la periurbanización. 


\subsection{Análisis histórico del cambio de uso del suelo}

La descripción del periodo, que abarcó desde la fundación de la ciudad en la época colonial hasta el inicio de la década de los ochenta del siglo pasado, proviene de una revisión bibliográfica que permitió clarificar las implicaciones locales del crecimiento urbano y su relación con las transformaciones ambientales ocasionadas en la cuenca baja del río Grijalva. La revisión bibliográfica y documental se concretó en un análisis de información histórica, social y económica (Allub y Michel, 1979; Capdepont-Ballina y Marín-Olán, 2014; Chávez-Jiménez, 2007; CEPAL, 2008; Flores-Santiago, 1987; Murillo, 2004; Pinkus-Rendón y Contreras-Sánchez, 2012; Ruiz-Abreu, 2002; Salazar-Ledesma, 2000); cartográfica y estadística (Cerna et al., 2011; Consejo Nacional de Población [CONAPO], 2006; Gurría-Lacroix, Castel y Guzmán, 1982; IMPLAN, 2008; Instituto Nacional de Estadística y Geografía [INEGI], 2000; RELIEFWEB (2007); así como ambiental y geográfica (Arreguín-Cortés, Rubio-Gutiérrez, Domínguez-Mora y Luna-Cruz, 2014; Díaz-Perera, 2014; FAO, 2015; Navarro y Toledo, 2008; Sánchez-Munguía, 2005). También se consultaron métodos sobre modelización geomática del cambio de uso del suelo (Eastman, 2012; Palacio et al., 2004). Esta información bibliográfica proviene de publicaciones periódicas, libros de texto, tesis e informes técnicos gubernamentales.

Para delimitar la zona urbana de acuerdo con el Programa de Desarrollo Urbano del Centro de Población de la Ciudad de Villahermosa y Centros Metropolitanos del Municipio de Centro, Tabasco 20082030 (IMPLAN, 2008) se recopiló una imagen LANDSAT 8 del 2015, cuyas bandas 7, 6 y 4 fueron combinadas en falso color con el software Arc Gis ${ }^{\circledR}$ 10.2.2. Por otro lado, el mapa de ocupación del suelo por etapas de Villahermosa se obtuvo de la base de datos Ciudades Capitales (INEGI, 2000). Este mapa fue digitalizado mediante software Arc Gis ${ }^{\circledR}$ 10.2.2.

\subsection{Modelización del cambio de uso del suelo de 1984 a 2008}

El análisis multitemporal se realizó mediante el modelizador de cambio de uso del suelo (Land Change Modeler for Ecological Sustainability), el cual se basó en tres mapas de los años 1984, 2000 y 2008, escala 1:10,000: Datum WGS84-Proyección UTM, zona 15N en formato raster. Previamente estos mapas fueron elaborados mediante digitalización en pantalla, con el software Arc Gis ${ }^{\circledR}$ 10.2.2. Los dos periodos considerados fueron de 1984 a 2000 y de 2000 a 2008. Los resultados incluyen los cambios netos del área de cada una de las siete categorías (vegetación arbórea, humedales, pastizal, terrenos baldíos, industrial, carreteras y urbano). Las tasas de cambio de uso del suelo se calcularon mediante la fórmula de Palacio et al. (2004): $\mathrm{Td}=[(\mathrm{S} 2 / \mathrm{S} 1)(1 / \mathrm{n})-1]^{*} 100$ donde $\mathrm{S}_{1}=$ área cubierta al inicio del periodo; $\mathrm{S}_{2}=$ área cubierta al final del periodo; $\mathrm{n}=$ número de años del periodo, $\mathrm{y} \mathrm{Td}$ = tasa de cambio anual expresada en porcentaje.

\subsection{Modelización de cambios con Cadenas de Markov y Autómatas Celulares de 2020 a 2040}

Con el módulo Markov de IDRISI Selva ${ }^{\circledR}$ se crearon tres matrices de probabilidad de transición. El método consistió en cruzar mapas de uso del suelo en dos periodos de tiempo, para crear una matriz de probabilidad de cambio en un tercer período (Eastman, 2012). Para cada proyección, el módulo generó una matriz de probabilidades de cambios, una matriz de áreas de cambio que contiene el número de píxeles que se espera cambien de una clase de uso a otra durante un período de tiempo y una colección de imágenes de áreas de adecuación/aptitud (Eastman, 2012). La primera matriz fue 2000-2008 (proyección 2020), después, se elaboraron las matrices 2008-2020 (proyección 2030) y 2008-2020 (proyección 2040). Posteriormente, con el módulo CA-Markov de IDRISI Selva ${ }^{\circledR}$ se construyeron escenarios espaciales a partir de la combinación de un mapa de uso de suelo base, la matriz de áreas de cambio y la colección de imágenes de áreas de adecuación/aptitud construidas en Markov. El modelo se puso en funcionamiento con 12 interacciones y un filtro de contigüidad de $5^{\times 5}$ píxeles para predecir cambios celulares significativos (Eastman, 2012). El primer escenario espacial creado en 2020 sirvió de base para crear los otros en 2030 y 2040. Los cortes históricos del crecimiento urbano, el uso urbano de los mapas 1984, 2000, 2008, y los escenarios urbanos 2020, 2030 y 2040 elaborados con Cadenas de Markov y Autómatas Celulares, fueron multiplicados mediante el comando Image Calculator el software IDRISI Selva ${ }^{\circledR}$ para la creación del mapa de la serie de tiempo de crecimiento urbano de la ciudad. 
Figura 4. Evolución demográfica y de la mancha de ocupación del suelo. Proyección hasta 2030. escenarios en la Ciudad de Villahermosa, México

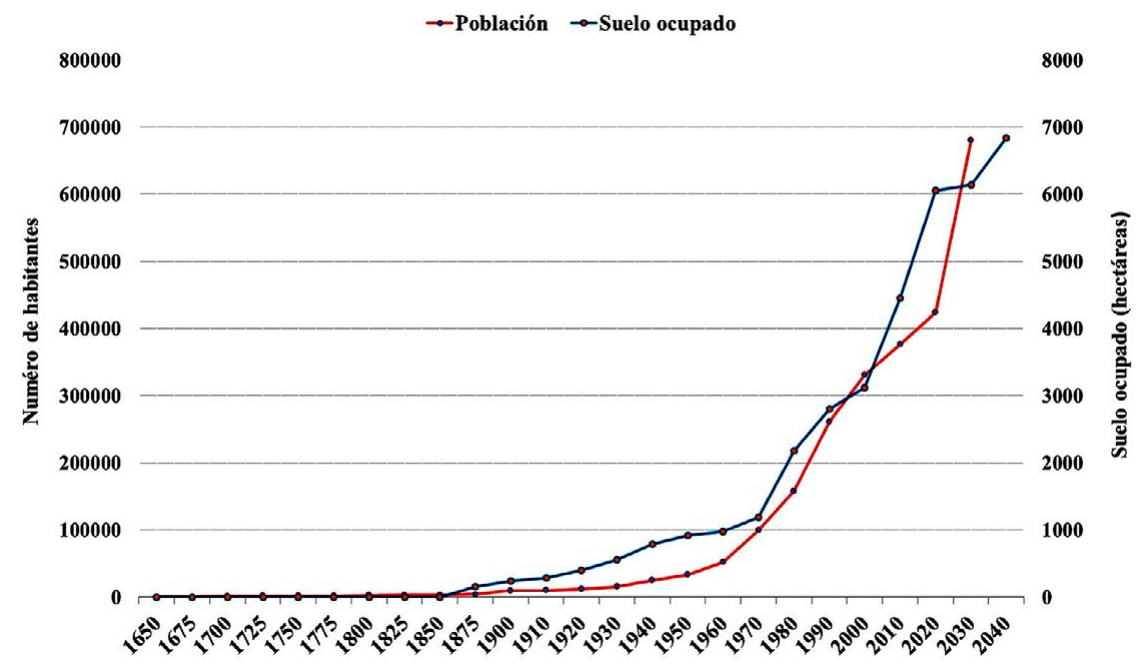

Fuentes: Evolución demográfica: Cerna et al., 2011; CONAPO, 2006; Gurría-Lacroix et al., 1982; Moreno-Amador, 2014; Torruco, 2014. Ocupación del suelo IMPLAN, 2008. Elaboración propia.

\section{Resultados}

\subsection{La Villa San Juan Bautista y primeras modificaciones en la red fluvial (siglos XVII-XIX)}

La Villa San Juan Bautista registró 365 pobladores 75 años después de su fundación, los cuales aumentaron aproximadamente a 5.660 habitantes en 1676 para reducirse a 2.701 habitantes en 1794. Este mínimo crecimiento demográfico perduró durante los últimos años de la época colonial e inicios del México independiente (1794 - 1823), pues sólo se sumaron 2.120 pobladores (figura 4). San Juan Bautista estuvo dividido en barrios rodeados por extensos humedales y a escasos kilómetros de la villa se establecieron varios pueblos (figura 2), que en el presente son zonas habitacionales densamente pobladas (figura 5).

Figura 5. Serie de tiempo del crecimiento de la ciudad de Villahermosa y escenarios hasta 2040

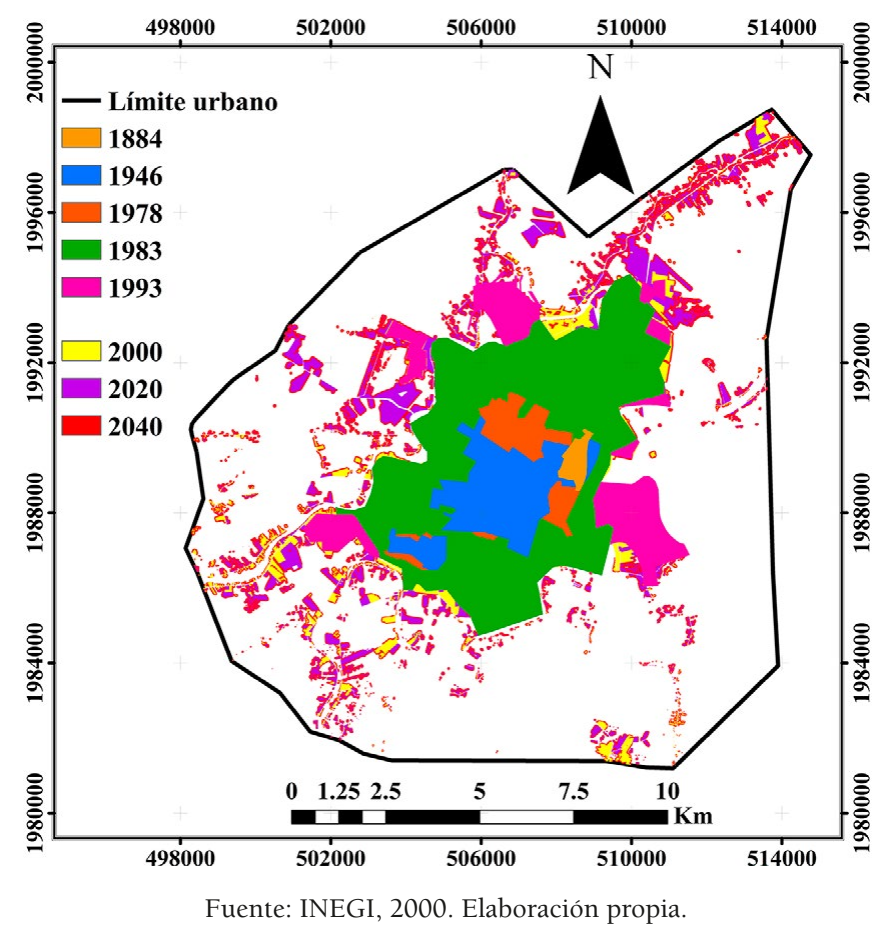


Las primeras modificaciones de la red fluvial en la cuenca del río Grijalva se registraron a finales de ese siglo con la formación natural e inducida del rompido o dique de Nueva Zelandia (figura 6). En 1675 este rompido desvió al río Mezcalapa al este y su mayor cauce fluyó por río Mezcalapa Viejo, antes de unirse la red de drenaje de los ríos de la Sierra a dos kilómetros al sur de San Juan Bautista, antes de converger con el río Grijalva.

\subsection{Impacto de los programas de desarrollo hidráulico y agropecuario en el siglo $X X$}

En el siglo XX se aplicaron programas de desarrollo económico que propiciaron crecimiento demográfico y urbano en Villahermosa principalmente. Este desarrollo urbano se continuó con un modelo basado en la protección contra las inundaciones y el cambio de uso de suelo de los humedales y sus zonas de vegetación asociadas en las áreas de inundación temporal, tasas de deforestación por cambio de uso de suelo y la construcción de infraestructura hidráulica para almacenar y desviar agua. Al iniciar el siglo XX Villahermosa ocupaba cerca de 160 ha (figura 4) y en la cuenca baja del río Grijalva continuó la transformación de la red fluvial superficial con la construcción de cuatro rompidos (figura 6). En 1904, el rompido de la Pigua unió el río Carrizal con el Grijalva al este de San Juan Bautista, con lo cual la ciudad quedó rodeada de ríos y vulnerable a las inundaciones. Para proteger la ciudad, en 1932 el rompido Samaria disminuyó el caudal del río Carrizal, pero inundó la Chontalpa, ubicada entre los ríos Cuxcuxapa y González. Por último en 1940, a través del rompido las Cañas fluyó agua de la Chontalpa hacia el río Medellín, que se unió al Grijalva.

En la década de los cincuenta del siglo pasado, ,la población en Villahermosa aumentó 2.5 veces con respecto a las primeras cinco décadas de ese mismo siglo (figura 4), pues la ciudad quedó comunicada por vía terrestre y hubo obras para controlar las inundaciones. Además, este crecimiento fue favorecido por los programas agropecuarios. En 1960 se registraron 18.684 habitantes más en Tabasco y Villahermosa incrementó 1.5 veces su área de 1946 a 1964 (figura 4).

\subsection{El boom petrolero a finales del siglo $X X$ y las inundaciones del siglo XXI}

El descubrimiento de nuevos yacimientos petrolíferos en el sureste de México inició un intenso proceso de explotación de hidrocarburos en la cuenca Grijalva y mar adyacente, que en los años setenta se reflejó en la máxima tasa de crecimiento demográfico al incorporarse 58.651 habitantes (figura 4), lo cual ejerció mayor presión sobre el sistema natural al provocar el crecimiento de la ciudad de Villahermosa (figuras 5 y 7 ).

En los últimos 20 años del siglo XX la población de Villahermosa aumentó 172.630 habitantes (figura 4) y la mancha urbana (zonas urbana, industrial y carreteras) se incrementó 1.010 ha de 1984 a 2000 (Tabla 1). En 1984, el pastizal, la vegetación arbórea y los humedales ocupaban aún el 85,4 \% del área de Villahermosa (Tabla 2) y la mayor parte de la vegetación arbórea estaba próxima a los ecosistemas acuáticos en zonas aún no urbanizadas. Mientras que, la zona urbana sólo ocupaba 10,6 \% del territorio (Tabla 2). Para el 2000, la vegetación arbórea perdió 2.384 ha y los humedales 76 ha. En contraste, el área de pastizal y la zona urbana aumentaron 1.507 y 942 ha (Tabla 2).

Posteriormente, en el periodo 2000-2008, la pérdida de áreas de vegetación arbórea (1,624ha) y de humedales (213 ha) aumentó en comparación con el periodo anterior, con amplias tasas de cambio (-7.45 y -1.13); mientras que, el pastizal (540 ha) y la zona urbana (1,334 ha) continuaron su avance (figura 7), ya que el crecimiento urbano más espacio para vivienda, centros comerciales y servicios de educación y salud. Durante los 24 años (1984-2008), la vegetación arbórea y los humedales perdieron 4,008 y 289 ha. En cambio, el pastizal y la zona urbana aumentaron 2.047 y 2.276 ha, lo que representa el mayor impactos en las últimas tres décadas (Tabla 1).

En la proyección de cambios de uso del suelo de 2008 al 2020 se mantuvo la tendencia de la sustitución de la vegetación arbórea y los humedales por el pastizal y el uso urbano, alcanzando las 15.697 ha totales. El análisis de los cambios netos mostró que los humedales, la vegetación arbórea y el pastizal perderán 2.593 ha y el uso urbano aumentará casi en la misma proporción, hasta una cifra de 2.480 ha (Tabla 2). Del 2020 al 2030, la vegetación arbórea y los humedales cubrirán 2.719 ha del área total; mientras que, el pastizal y el uso urbano ocuparán 17.059 ha. La vegetación arbórea perderá 34 ha, los humedales 32 ha, y el pastizal 49 ha. En cambio, el uso urbano aumentará 79 ha (Tabla 2). 
Figura 6. Red fluvial superficial en la cuenca baja del río Grijalva, sureste de México

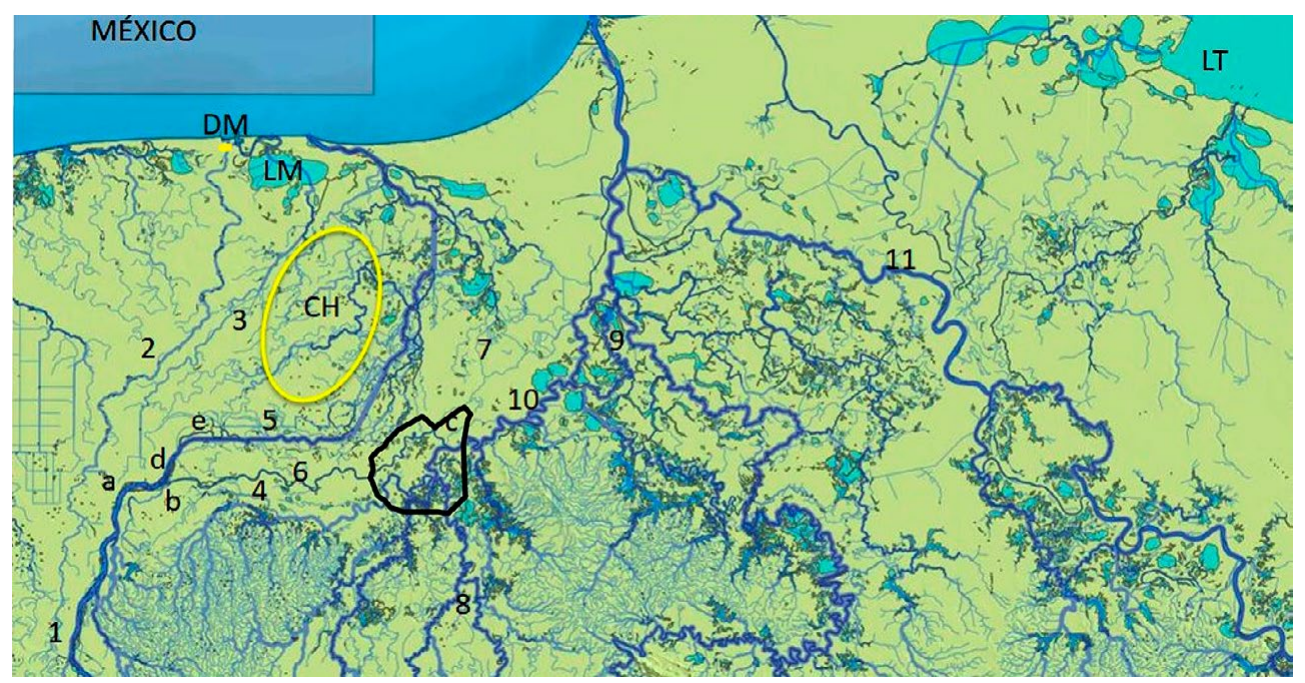

Nota: rompidos: $a=$ Nueva Zelandia, b=Manga de Clavo, c=La Pigüa, d= Samaria y e=del Cañas; ríos: $1=$ Mezcalapa, $2=$ Seco (sin flujo), 3=Cuxcuxapa, 4= Mezcalapa Viejo, 5=Samaria, 6=Carrizal, 7=González, 8=red fluvial de la Sierra, 9=red fluvial Tepetitán-Chilapa, 10=Grijalva, $11=$ Usumacinta; lagunas costeras: LM= laguna Mecoacán y LT= laguna de Términos; otros: DM= antigua desembocadura del Río Mezcalapa: $\mathrm{CH}=$ Chontalpa, y Borde con línea negra= Zona metropolitana de Villahermosa.

Fuente: Sánchez, et al., 2015. Elaboración propia.

Sin embargo, el periodo 2030-2040, será crítico, porque la vegetación arbórea y los humedales cubrirán solamente 2.332 ha de la superficie total; mientras que, el pastizal y el uso urbano ocuparán la mayor superficie de todo el periodo con 17.529 ha. En relación a los cambios netos, la vegetación arbórea perderá 278 ha, los humedales, 109 ha, y el pastizal 217 ha. En cambio, el uso urbano aumentará 689 ha (Tabla 2).

Figura 7. Evolución del uso del suelo 1984-2000-2008 y escenarios 2020-2030-2040 en la ciudad de Villahermosa
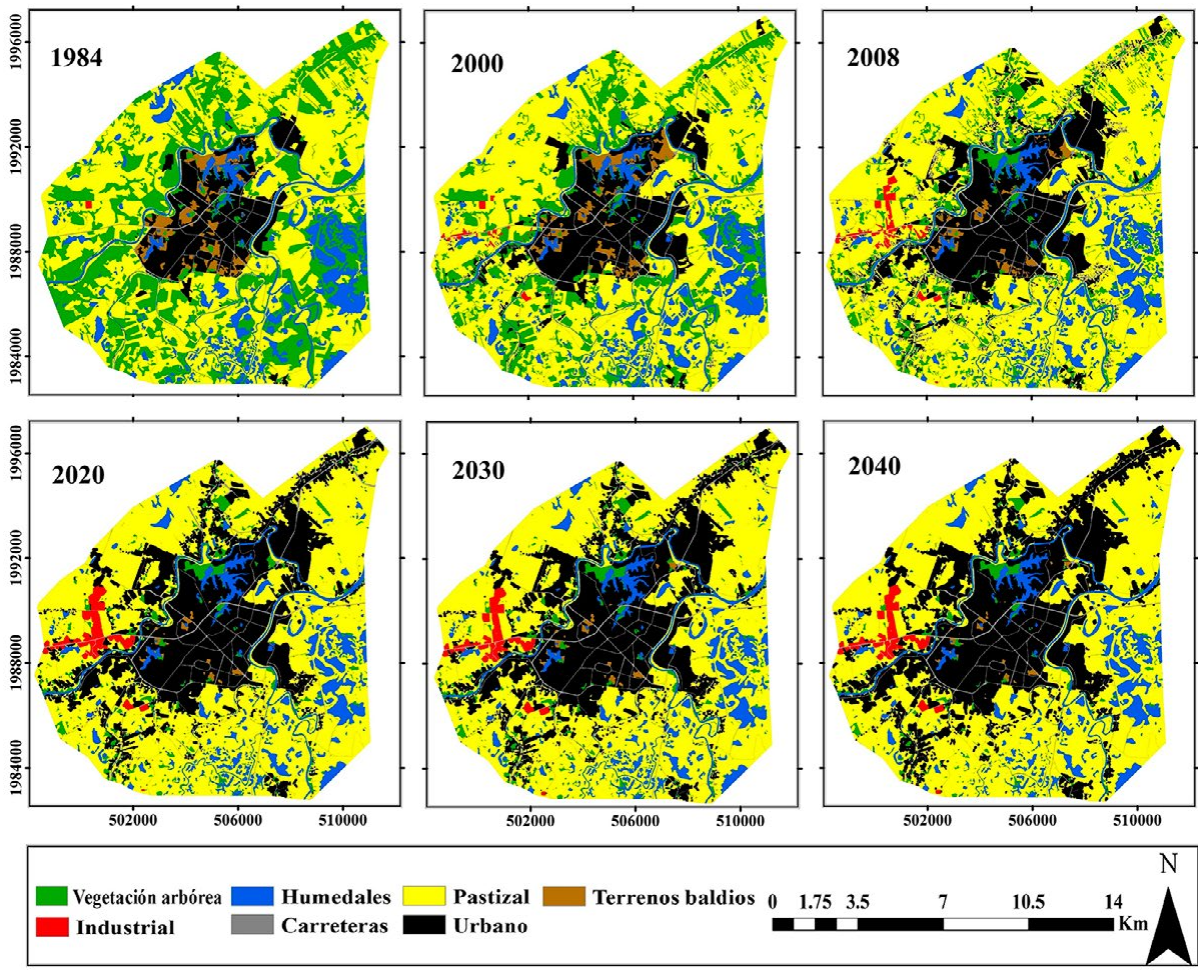

Elaboración propia. 
Tabla 1. Cambio de uso del suelo y crecimiento urbano en hectáreas en la ciudad de Villahermosa

\begin{tabular}{|c|c|c|c|c|c|c|c|}
\hline Categoría & 1984 & 2000 & 2008 & $84-00$ & $00-08$ & $84-08$ & TC 84-08 \\
\hline Vegetación arbórea & 5,901 & 3,517 & 1,893 & 2,384 & 1,624 & 4,008 & -4.63 \\
\hline Humedales & 2,533 & 2,457 & 2,244 & 76 & 213 & 289 & -0.50 \\
\hline Pastizal & 9,192 & 10,699 & 11,239 & $-1,507$ & -540 & $-2,047$ & 0.84 \\
\hline Terrenos baldíos & 465 & 407 & 203 & 58 & 204 & 262 & -3.40 \\
\hline Industrial & 10 & 64 & 184 & -54 & -120 & -174 & 12.81 \\
\hline Carreteras & 373 & 387 & 435 & -14 & -48 & -62 & 0.65 \\
\hline Urbano & 2,182 & 3,124 & 4,458 & -942 & $-1,334$ & $-2,276$ & 3.02 \\
\hline
\end{tabular}

Nota: TC=Tasas de cambio de uso del suelo en porcentaje.

Elaboración propia.

Tabla 2. Escenarios del cambio de uso del suelo y crecimiento urbano en hectáreas en la ciudad de Villahermosa

\begin{tabular}{|c|c|c|c|c|c|}
\hline Categoría & 2020 & 2030 & 2040 & TC 20-30 & TC 30-40 \\
\hline Vegetación arbórea & 756 & 722 & 444 & -34 & -278 \\
\hline Humedales & 1,965 & 1,997 & 1,888 & 32 & -109 \\
\hline Pastizal & 10,971 & 10,922 & 10,705 & -49 & -217 \\
\hline Urbano & 6,058 & 6,137 & 6,824 & 79 & 687 \\
\hline
\end{tabular}

Nota: TC=Tasas de cambio de uso del suelo en porcentaje.

Elaboración propia.

\section{Discusión de resultados}

\subsection{Crecimiento urbano desde la fundación hasta finales del siglo XIX}

La integración histórica y el análisis de los cambios de usos de suelo y sus proyecciones mostraron un mínimo crecimiento asociado con Villahermosa, hasta en el último tercio del siglo XX, cuando se inció el proceso de metropolización (figura 4). A lo largo de su historia su crecimiento se ha realizado mediante la sustitución de humedales y vegetación por zonas habitacionales e infraestructura urbana. En paralelo fueron necesarias importantes modificaciones de la red fluvial superficial para protegerla de las inundaciones (Chávez-Jiménez, 2007; Izquierdo y Bustos, 1984; Navarro y Toledo, 2008; Salazar-Ledesma, 2002; Ruiz-Abreu, 2002; Ruz, 2002).

Desde 75 años después de su fundación hasta finales de la época colonial en 1823, el crecimiento reducido que sólo permitió alcanzar los 4.456 habitantes (figura 4), lo que se ha explicado principalmente por causas socioeconómicas y de salud pública como el decrecimiento inicial de la población indígena, las enfermedades provocadas a los españoles por las temperaturas climáticas extremas, la carencia de drenaje y las frecuentes precipitaciones con inundaciones, así como la dificultad de concentrar con éxito a las comunidades indígenas en los centros urbanos (Arrieta, 1994, Salazar-Ledesma, 2000; Moreno-Amador, 2014). Esto último estuvo vinculado al éxito del comercio de los productos de la ganadería, del cacao y del palo de tinte (Haematoxylum campechianum) que fueron mayoritariamente registrados en la Real Aduana de Tabasco, ubicada en la actual Villahermosa (Ruz, 2002). Además, la declaración de San Juan Bautista como puerto menor y el regreso de la administración virreinal en 1795, promovió la concentración de las actividades comerciales, políticas, sociales y culturales (Ruiz-Abreu, 2002; Torruco, 2014). A las condiciones ambientales extremas y la compleja hidrología superficial se sumaron negativamente para el crecimiento demográfico, la inestabilidad social causada por las incursiones de los piratas, las alianzas de los nativos con los piratas, y el proteccionismo económico de la Corona española para favorecer otras provincias, lo que alentó la emigración hacia la antigüa provincia Chiapas (Chávez-Jiménez, 2007; Izquierdo y Bustos, 1984; Moreno-Amador, 2014; Ruiz-Abreu, 2002; Ruz, 2002; Salazar-Ledesma, 2002; 2008). Además en el siglo XIX, la población disminuyó (figura 4) por las epidemias de cólera (1833 y 1850) y viruela en 1836 (Torruco, 2014). 
En estos siglos, las primeras transformaciones del área de drenaje superficial de los ríos en la cuenca baja del Grijalva se dieron por la construcción de los rompidos o derivaciones de cauce (figura 6), mientras que las modificaciones en la ciudad de Villahermosa fueron menores debido a su bajo crecimiento (figuras 4 y 5). La mayoría de los autores coinciden en que el objetivo del rompido Nueva Zelanda (figura 6) fue cambiar el curso del río Mezcalapa para evitar las incursiones de los piratas por dicho río (Izquierdo y Bustos, 1984; Salazar-Ledesma, 2002). Este rompido interrumpió la descarga independiente del río Mezcalapa al Golfo de México (Salazar-Ledesma, 2008), pues antes del siglo XVII, el río Mezcalapa y la red fluvial de la Sierra, que retoman río abajo el nombre de Grijalva, descargaban independientemente al Golfo de México (figura 6), junto a la laguna de Mecoacán y después de converger con el río Usumacinta, respectivamente.

\subsection{Expansión urbana y metropolización}

En el siglo XX se registró un incremento notorio de Villahermosa. En la primera mitad del siglo XX la ciudad ocupó 472 ha con 23.974 pobladores (figura 4). En la cuenca baja dominaron las plantaciones, principalmente de plátano y cacao, orientadas al mercado internacional (Allub y Michel, 1979). También se realizó la construcción de los restantes cuatro rompidos (figura 6) destinados a evitar inundaciones en Villahermosa, lo cual no se logró y además otras zonas de la cuenca baja del río Grijalva fueron anegadas (Chávez-Jiménez, 2007; Navarro y Toledo, 2008; Ruiz-Abreu, 2002; Salazar-Ledesma, 2002). Los cinco rompidos representan la primera modificación de la red superficial de drenaje de la cuenca baja del Grijalva, ya que que se interrumpieron cauces, propiciaron nuevos ríos o aumentaron el flujo a algunos existentes. Por ejemplo se interrumpió la descarga del río Mezcalapa al Golfo de México, Villahermosa quedó rodeada de ríos, la red fluvial de la Sierra recibió las descarga de los ríos Mezcalapa Viejo y Carrizal, y los ríos Samaría y González inundaron zonas y poblados ubicados al norte de Villahermosa antes de descarga en el sur del golfo de México (figura 6). Además, los rompidos originaron la desconexión hidráulica de humedales, causaron pérdida de biodiversidad, aislaron poblaciones en la cuenca baja del río Grijalva y afectaron tanto las actividades urbanas como a la economía regional (Navarro y Toledo, 2008; Salazar-Ledesma, 2008).

A diferencia de la primera mitad del siglo XX, en la segunda se magnificó el crecimiento Villahermosa, pues en los últimos años se llegó a las 2.492 ha ocupadas y los con 297.268 habitantes (figura 4). La expansión urbana estuvo relacionada, en primer lugar, con el impulso de la ganadería extensiva para abastecer al mercado nacional mediante el Plan Chontalpa (1965-1976) y el Programa de Desarrollo Rural Integrado para el Trópico Húmedo. En segundo lugar, fue determinante el auge petrolero que comenzó en los setenta (Allub y Michel, 1979; Capdepont-Ballina y Marín-Olán, 2014; Flores-Santiago, 1987; Hernández, 2011; Lezama, 1987). Dichos programas estuvieron caracterizados por la creación de nuevos centros urbanos y el crecimiento de algunos existentes como Villahermosa, construcción de nuevas carreteras, aceleradas tasas de deforestación por cambio de uso de suelo y la construcción de infraestructura hidráulica (Flores-Santiago, 1987; Gracia y Fuentes, 2004; Murillo, 2004; Murillo y Martínez, 2010; Navarro y Toledo, 2008; Pinkus-Rendón y Contreras-Sánchez, 2012; Sánchez-Munguía, 2005; Zavala et al., 2009). Las infraestructuras hidráulicas se construyeron para almacenar y desviar agua con los objetivos de controlar las inundaciones y favorecer el drenaje en áreas con potencial agrícola e impulsar proyectos de irrigación (Allub y Michel, 1979; Flores-Santiago, 1987). Por lo mismo, el contraste entre las dos mitades del siglo XX con respecto al crecimiento urbano (figura 5) y programas económicos dominantes se reflejó también en la marcada pérdida de humedales y vegetación arbórea por cambio a uso de suelo urbano en Villahermosa. La continuación de las mencionadas transformaciones en la red hidrológica en la segunda mitad del siglo XX en la cuenca baja del río Grijalva por la construcción del ferrocarril del Sureste, red de carreteras, presas, bordos, drenes, cegamientos y re-encauzamientos de cursos de ríos para la derivación, contención de agua y protección de la ciudad de Villahermosa (Gracia y Fuentes, 2004; Navarro y Toledo, 2008) modificó la variación espacial y temporal natural del volumen de agua, lo que a su vez desconectó hidráulicamente a muchos humedales y sus zonas de anegamiento, modificó sus volúmenes y afectó a la biodiversidad acuática (Sánchez et al., 2015). Estos cambios se sumaron a los efectos de la construcción de los cinco rompidos (1675-1940), en el sentido de que la alteración afectó el funcionamiento de los ecosistemas y algunas prácticas productivas en la cuenca baja de los ríos Mezcalapa-Grijalva. Por ejemplo, las presas por su función de almacenamiento y las carreteras por su diseño de construcción han impac- 
tado la biodiversidad acuática, el drenaje natural de la red fluvial al impedir la conexión de los ríos con los humedales fluviales y modificar los volúmenes de los cauces (Cerna et al., 2011; Sánchez et al., 2015).

El marcado incremento de la población en Villahermosa en la década de los cincuenta respecto a las primeras cinco décadas del siglo XX (figura 4) coincide con los resultados publicados por Allub y Michel (1979), quienes registraron una tasa de crecimiento anual mayor al 2,4\%. Este incremento se puede vincular al inicio del funcionamiento de la carretera que comunicó a Villahermosa con el centro del país. También, hay registros de obras dentro de la ciudad para controlar los volúmenes naturales de agua que causaban inundaciones, rellenar los humedales conectados con el río Grijalva y ampliar la ciudad, como es el caso del malecón de Villahermosa (Gracia y Fuentes, 2004; Díaz-Perera, 2014). La expansión de los centros urbanos en esta década, promovió la deforestación de 85,450 ha de selvas distribuidas en ejidos y propiedad privada (Sánchez-Munguía, 2005). La población y el área de la ciudad siguieron en incremento durante los 60’s (figura 4). De 1964 a 1974, Villahermosa se incrementó 1.3 veces su área (figura 4), lo que coincide con Arrieta (1994), quien mencionó que en estos años la ciudad se consolidó como el centro urbano más importante y extenso de la cuenca baja del río Grijalva. Este crecimiento urbano fue acompañado con la construcción de bordos de contención para regular las anegaciones, así como la invasión de humedales urbanos que habían funcionado como límites naturales del establecimiento de nuevas calles y colonias, entre las cuales estuvo la integración de los tres antiguos pueblos circundantes como colonias populares.

En la década de los sesenta, la expansión de tres veces del área de Villahermosa se hizo bajo el impulso de la construcción de obras emblemáticas, así como del trazado de infraestructuras viales y servicios educativos, de recreación, culturales y administrativos, como la Ciudad Universitaria, centros deportivos, hospitales, puentes, mercados, avenidas y parques (Capdepont-Ballina y Marín-Olán, 2014; Cerna et al., 2011; Díaz-Perera, 2014). Sin embargo, dicho crecimiento estuvo aún confinado dentro de los límites naturales de los ríos Mezcalapa Viejo, Carrizal y Grijalva que bordeaban a la ciudad, aunque ya había sobrepasado el límite del río Carrizal en 1974 (Díaz-Perera, 2014). Simultáneamente en la cuenca baja del río Grijalva, el incremento de la producción de ganadería extensiva y del cultivo de granos básicos generó la pérdida de los servicios ambientales que proveía la selva (Allub y Michel, 1979; Arrieta, 1994; Flores-Santiago, 1987), ya que fueron talados cerca de 50.000 ha de bosque tropical perennifolio y otras comunidades florísticas del trópico húmedo (Murillo, 2004; Sánchez-Munguía, 2005). En este contexto, los cambios en las áreas y los tiempos de anegación provocados por la variación antrópica de los ciclos de inundación afectaron las prácticas agropecuarias por la interrupción del rejuvenecimiento cíclico de los suelos y la eliminación del aporte de aluviones (Toledo, Vázquez-Botello y Herzig, 1987).

Con el boom petrolero, iniciado entre 1973 y 1980, el desarrollo económico basado en el mercado agropecuario nacional derivó hacia la dependencia de los hidrocarburos (Allub y Michel, 1979; Lezama, 1987). En los setenta, la población de Tabasco alcanzó su máxima tasa de crecimiento. El PIB del Estado registró una tasa media anual de $21 \%$, en 1978 y más de tres cuartas partes del total provino de la producción de hidrocarburos. En ocho años la participación del sector petrolero aumentó 20,9\%; mientras que el sector agropecuario descendió a más de la mitad (Lezama, 1987). Sin embargo, la acelerada deforestación continuó por el incremento de zonas para actividades agropecuarias (Zavala y Castillo, 2007). En la década de los setenta, dicha deforestación redujo la selva a 146.485 ha (Sánchez-Munguía, 2005), de las cuales se perdieron 105.406 ha más en 1990. Esto significó que en 40 años las selvas disminuyeron del 21,7\% al 1,6\% del área de Tabasco (Sánchez-Munguía, 2005). En 1980 el Estado se convirtió en el mayor productor de hidrocarburos del país, cuando las reservas de crudo aumentaron de 60.000 millones de barriles (Allub y Michel, 1979; Capdepont-Ballina y Marín-Olán, 2014). Los ecosistemas ya estaban afectados antes de la llegada de Petróleos Mexicanos, por las políticas de colonización, los planes hidráulicos, agropecuarios y la ganaderización extensiva (Sánchez-Salazar, 1990). Sin embargo, el boom petrolero aportó deterioro ambiental en las áreas de incorporación de la actividad, como aquellas en donde la concentración industrial y el acelerado crecimiento demográfico provocaron excesivas presiones sobre los ecosistemas de la cuenca baja del río Grijalva. Por ejemplo, la construcción de carreteras y drenes de paso a través de las zonas de anegación de los humedales para acceder a los pozos, aportaron a la modificación de los patrones de circulación natural del agua, ciclos biogeoquímicos y la biodiversidad de la fauna acuática (Allub y Michel, 1979; Capdepont-Ballina y Marín-Olán, 2014; Sánchez et al., 2015). El grado de afectación en sedimentos, agua, suelo, organismos y población humana provocado por las actividades 
relacionadas con la industria petrolera está aún pendiente de resolver en la cuenca baja del río Grijalva (Allub y Michel, 1979; Pinkus-Rendón y Contreras-Sánchez, 2012).

A partir de 1974, la ciudad de Villahermosa sobrepasó el límite del río Carrizal y en 1984 inició la conurbanización con el establecimiento de zonas habitacionales y su consolidación entre los años 1993 y 2008 (figura 7). En los ochenta, los humedales y los pastizales de uso agropecuario aún ocupaban más área que la urbana (Tabla 1), pero la petrolización también influyó en la construcción de zonas industriales, habitacionales y comerciales (Capdepont-Ballina y Marín-Olán, 2014; Díaz-Perera, 2014), que además de aumentar los servicios municipales, saturaron los espacios disponibles dentro de los límites urbanos y provocaron un incipiente desarrollo periurbano (figura 7). En esta década se construyó el malecón en el margen opuesto al anterior en el río Grijalva y se modificó la laguna La Pólvora, cuyas zonas de anegamiento temporal que fueron rellenadas desde los 50's (Díaz-Perera, 2014). Las orillas de los dos embalses de la Pólvora fueron reconstruidas con cemento y reducidos a un área de 50,150 $\mathrm{m}^{2}$ dentro de un parque recreativo, que a su vez está rodeado de edificios de oficinas de gobierno y educativos así como del Mercado de la Sierra, los cuales no descargan aguas residuales en la laguna la Pólvora, pero sí han afectado la calidad del agua y la biodiversidad acuática de la misma por escorrentía (Sánchez et al., 2012). También, varios ejidos en la rivera del Grijalva comenzaron a ocuparse por ser zonas de menor valor, aunque de mayor vulnerabilidad (Díaz-Perera, 2014). Este crecimiento urbano promovió la ampliación de carreteras y el cambio de uso del suelo rural por urbano fuera de sus límites, ya que la accesibilidad dada por las vialidades es un factor que favorece la urbanización (Junliang, Xiaolu y Shoushuai, 2010).

La saturación urbana en el centro de Villahermosa en los ochenta favoreció la periurbanización en la siguiente década. En este proceso de metropolización se repitió el relleno de humedales, la deficiencia de servicios de drenaje y la alta vulnerabilidad a inundaciones (Hernández, 2011; Cerna et al., 2011). En el periodo 1984-2008, la pérdida de la vegetación arbórea, estimada en este estudio, resultó cuatro veces mayor que la registrada en las cuencas Grijalva y Usumacinta y en México (FAO, 2015; Kolb y Galicia, 2012). En un periodo similar (1984-2005), Zavala et al. (2009) registraron que los pastizales para la ganadería de bovinos y las actividades urbanas ocuparon el $60 \%$ y $9,1 \%$ respectivamente del área de Villahermosa. Mientras que las áreas con vegetación arbórea representaron el 25,3 \% y los humedales el $5,2 \%$ del territorio urbano. Los mismos autores mencionaron que el $74 \%$ del paisaje fue transformado en dicho periodo. La vegetación arbórea regula el clima local y el microclima urbano y en la actualidad, ambos servicios ambientales son más valorados, ya que el bienestar de los habitantes depende más de ellos debido al cambio climático global (Benítez, Pérez, Nava, Equihua y Álvarez, 2012). Sí en las próximas décadas, la pérdida de vegetación arbórea continúa por el crecimiento periurbano en la cuenca del Grijalva, Villahermosa estará más afectada. Podrían desaparecer los últimos remanentes de vegetación arbórea, como lo indicaron los escenarios 2020 - 2040 modelados en este estudio, con los consecuentes efectos ambientales, como la erosión del suelo, las sequías, inundaciones, pérdida de espacios para recreación humana y pérdida del hábitat de flora fauna silvestre de la región.

Durante 1984-2008, la tasa de cambio de uso del suelo de la vegetación arbórea en la ciudad de Villahermosa fue de $-4,63 \%$ (Tabla 1), la cual es cuatro veces mayor a la registrada en las cuencas de los ríos Grijalva y Usumacinta y en el país. En las cuencas bajas de los ríos Grijalva y Usumacinta, durante 1950 al 2000, ya se habían perdido alrededor de 83.518 ha de humedales a un ritmo de 3.341 ha en cada año (Sánchez-Munguía, 2005). De forma similar, Kolb y Galicia (2012) observaron que, durante 1993 y 2007, la tasa de deforestación en las cuencas Grijalva y Usumacinta fue de 0,90\%, y los informes de FAO (2015) destacaron a México con tasas de deforestación de -0,3\% durante 1990 y 2015. En estos 16 años, la pérdida de humedales estimada en este estudio vinculada al desarrollo urbano en Villahermosa continuó con su aislamiento hidráulico y el relleno de sus zonas de anegación. Corroborando estos estudios, Sánchez-Munguía (2005) cuantificó que el avance urbano de 2.296 ha entre 1990 y 2000 invadió humedales y eliminó las macrófitas acuáticas enraizadas que funcionan como vasos reguladores y zonas de conservación de biodiversidad. En el conjunto de la cuenca se calculó que el $60 \%$ de los humedales se perdió en los primeros ocho años del siglo XXI (Landgrave y Moreno-Casasola, 2012). La disminución del área, fragmentación y pérdida de humedales urbanos y rurales en Villahermosa, cuenca Grijalva y otras cuencas, se ha relacionado con la obstrucción de su interconexión hidráulica mediante canales, construcción de infraestructuras urbanas y de caminos, regulación del cauce de ríos para retención o desviación del agua, dragado de humedales para control de inundaciones y la extracción del agua para actividades agropecuarias (Hettiarachchi et al., 2014; Moreno-Casasola, 2008). 


\subsection{Pérdida de servicios ambientales y vulnerabilidad por expansión urbana}

A pesar de los servicios ambientales que los humedales han provisto y los mayores beneficios económicos recibidos por invertir en su conservación (Henny y Meutia, 2014; Maltby y Acreman, 2011); los proyectos de desarrollo urbano en Villahermosa, durante 1984-2008, continuaron con el aislamiento hidráulico de los humedales y el relleno de zonas de anegación que provocaron la pérdida de 289 ha de humedales (Tabla 1). En el 2008, solamente 548,55 ha de 2.244 ha ocupadas por humedales en Villahermosa (Tabla 1), habían sido decretadas como Áreas Naturales Protegidas. Por lo tanto, las 1.695 ha restantes están expuestas a seguir disminuyendo o desapareciendo por el crecimiento periurbano ante el retraso en la ejecución de las tres áreas propuestas en el Programa de Desarrollo Metropolitano 20082030 (IMPLAN, 2008), para regular el uso y conservar humedales, vegetación arbórea y zonas de pastizal: 5.715 ha para la Preservación, Conservación total y Regulación Hidrológica, 1.310 ha reservadas a la Preservación Ecológica para Mejoramiento y Compatibilidad Restringida y 174 ha de Valor Ambiental (figura 8). Sin embargo, su creación jurídica está aún pendiente según (Bazant, 2010; Orellana, Arenas, Marshall y Rivera, 2016) por las inconsistencias legales y administrativas en los programas de desarrollo urbano y ambiental vinculadas con la carencia de gobernanza municipal, unido a la insuficiente inversión y resultados no esperados. La tendencia a la pérdida de humedales y de vegetación sugerida en los modelos de cambio de uso de suelo para las tres décadas siguientes representa una alerta para los responsables de diseñar y aplicar programas de planeación urbana enfocados a mitigar o revertir dichas tendencias.

Adicionalmente, la inoperatividad de los programas y acciones de conservación, restauración y educación ambiental en los humedales bajo protección dentro de parques y sin regulación de Villahermosa se ha reflejado en que desde el inicio de la década de los noventa se ha registrado hipertrofia y valores elevados de contaminación fecal y de metales; así como menor diversidad de fauna acuática (Hansen, van Afferden y Torres, 2007; Sánchez et al., 2012). Estas condiciones de perturbación ambiental y pérdida de biodiversidad han sido frecuentemente relacionadas con la fragmentación de los humedales urbanos y el manejo inadecuado de las aguas de escorrentía y residuales (Bekessy et al., 2012; Henny y Meutia, 2014; Hettiarachchi et al., 2014), sobre todo en ciudades, como en Villahermosa. A ello debe sumarse, la insuficiencia de servicios municipales en zonas marginadas y asentamientos irregulares con la falta de inversión y actualización del sistema de drenaje para controlar las escorrentías y manejo de aguas residuales. En este ámbito, los cambios de actitud de la población con respecto al valor de sus ecosistemas es un factor que se añade a la degradación y disminución del área de los humedales (Hettiarachchi et al., 2014).

Figura 8. Áreas propuestas como: Preservación Ecológica para el Mejoramiento y Compatibilidad Restringida (PEM), Preservación, Conservación total y Regulación Hidrológica (PEC) y de Valor Ambiental (AV)

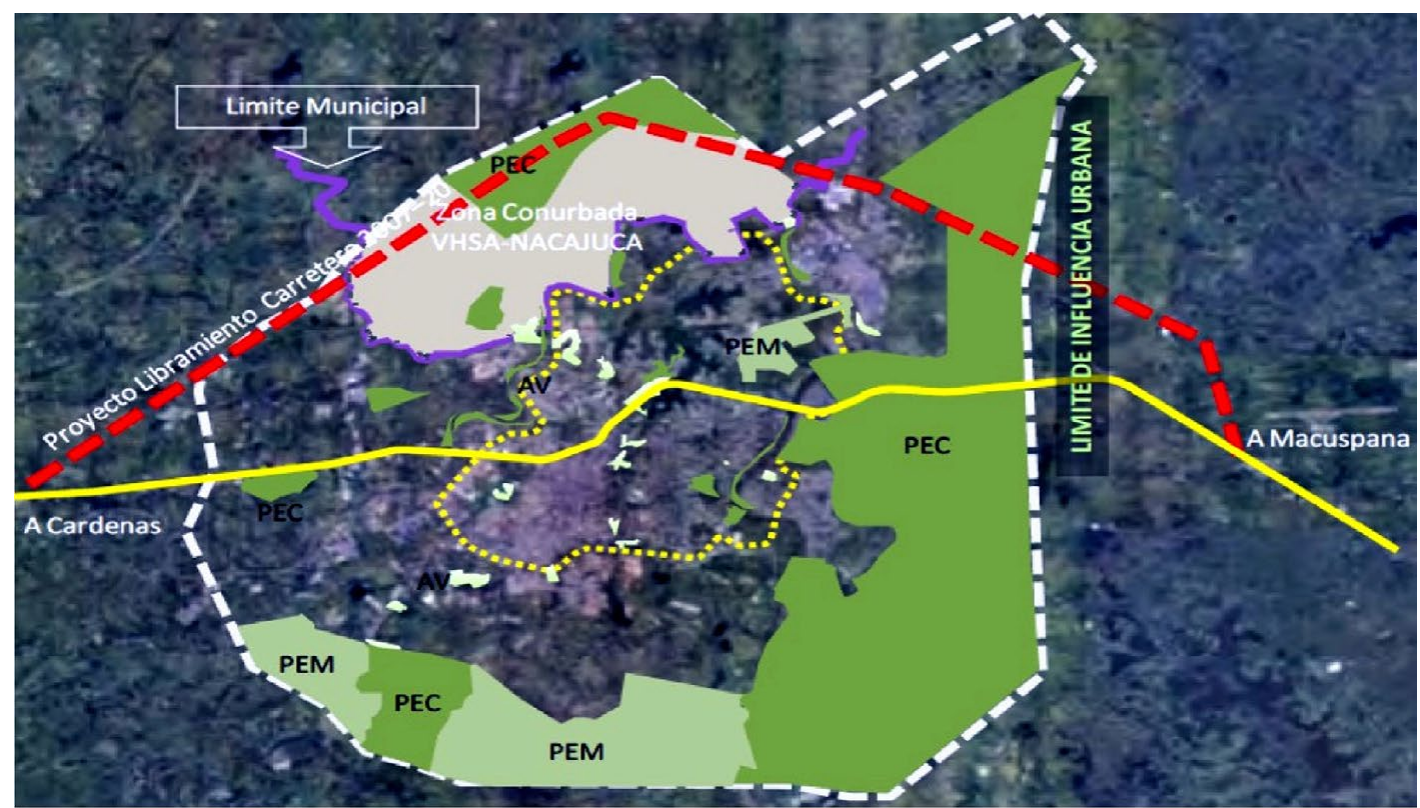

Fuente: IMPLAN, 2008. 
Las consecuencias de la inadecuada aplicación de políticas públicas de crecimiento urbano y la insuficiencia de ingresos de gran parte de la población para satisfacer sus necesidades de vivienda ha promovido: 1) el agotamiento de espacio en zonas altas y aptas para el desarrollo urbano, 2) los proyectos de infraestructura hidráulica para contener y desviar agua, 3) la proliferación de la construcción de carreteras y drenes de paso a través de las zonas de anegación de los humedales para acceder a las instalaciones de Petróleos Mexicanos, y 4) los planes de desarrollo de viviendas que periurbanizaron a la ciudad (Allub y Michel, 1979; Capdepont-Ballina y Marín-Olán, 2014; Cerna et al., 2011; Díaz-Perera, 2014). Estas condiciones han contribuido a la formación de espacios urbanos segregados con desigualdad económica y al deterioro ambiental en varias ciudades latinoamericanas (Azócar, Sanhueza y Henríquez, 2003; Benítez et al., 2012; Garza, 2010). Entre estas ciudades, Villahermosa tiene una posición poco envidiable. Por ejemplo, se han cuantificado 59 asentamientos irregulares ubicados en su mayoría en zonas de inundación temporal a finales del primer lustro de este siglo. Las políticas y obras que priorizaron la protección de la ciudad contra las inundaciones resultaron determinantes, ya que la reiterada práctica de rellenar los vasos reguladores y permitir asentamientos irregulares en áreas de anegación aumentó los problemas de marginación y la vulnerabilidad de la población urbana y suburbana. Incluso esa situación se agravaría por los flujos extremos máximos del ciclo de inundación natural. Por ejemplo, las inundaciones ocurridas en septiembre y octubre de 2007 (figura 9), cubrieron el 70\% del Estado, afectaron a cerca de 1.500 localidades, damnificaron al 75\% de la población, dañaron 570.000 hectáreas agrícolas con pérdidas de 462 millones de dólares y perjudicaron a cerca de 123.000 viviendas en todo el Estado, de las cuales 50.561 se ubicaban en Villahermosa (CEPAL, 2008; RELIEFWEB, 2007). Además, al sumar las inundaciones de 2007 y 2008, las pérdidas totales equivalieron al 33,3\% del PIB estatal (CEPAL, 2011). Álvarez y Tuñón (2016), Díaz-Perera (2014), Hernández (2011) y Perevochtchikova y Lezama (2010) coincidieron en relacionar estas inundaciones con: a) el manejo errático de las presas que sobrepasaron el nivel máximo ordinario en las temporadas de lluvias extremas, b) la nula intervención para conservar la vegetación marginal que favoreció el azolve de los ríos, c) algunas obras de ingeniería civil, y d) el desinterés gubernamental para regular los asentamientos irregulares en las áreas de inundación temporal en Villahermosa. Sin embargo, las inconsistencias sociales y ambientales continuaron, ya que para atender a la población más afectada por las inundaciones el gobierno del estado construyó fraccionamientos para su reubicación en áreas de humedales y vegetación arbórea (Cerna et al., 2011; Hernández, 2011). Por lo mismo, en ausencia de políticas restrictivas, el deterioro ambiental en Villahermosa y la cuenca baja del Grijalva puede ser mitigado mediante un marco normativo ambiental-urbano integral y de jurisdicción federal, estatal y municipal que regule la proliferación anárquica de obras de infraestructuras, promociones inmobiliarias e industriales y la exploración petrolera. Debe darse prioridad a la restricción del crecimiento urbano, impidiéndo el mismo en zonas que aún tienen características de reserva natural, como la llamada gran reserva sur de Villahermosa, y los márgenes de los ríos de la Sierra, Viejo Mezcalapa, Carrizal y Grijalva (Bazant, 2010).

Las obras hidráulicas construidas a principios de este siglo, para el control de las inundaciones (figura 10), se diseñaron a partir de las inundaciones de 1999 en Villahermosa (Arreguín-Cortés et al., 2014). Durante 1999 y 2002 se construyeron $80 \mathrm{~km}$ longitudinales de bordos de protección en la zona urbana y conurbada, pero principalmente en el margen derecho del río Carrizal (figura 6). Después en 2003 y 2004 se edificaron bordos en la red de los ríos de la Sierra y se instalaron 17 estaciones telemétricas automáticas en la planicie de inundación de la cuenca del río Grijalva. Entre 2005 y 2006 se construyó la obra de control de crecientes en el río Carrizal y se aumentaron 10 estaciones telemétricas en la zona montañosa de la cuenca del río Grijalva. Sin embargo en 2007, las obras, ya sea terminadas o inconclusas, no resistieron la inundación de octubre (Arreguín-Cortés et al., 2014). En respuesta en 2008, dos escotaduras fueron construidas en la planicie de inundación de la cuenca del río Grijalva para privilegiar el drenaje de la cuenca y proteger a Villahermosa. En 2009 se concluyó la edificación del vertedor margen izquierdo de la estructura de control en el río Carrizal (Arreguín-Cortés et al., 2014) y en 2010 se levantaron seis escotaduras adicionales. En 2011, la cortina de la estructura de control sobre el río Carrizal fue cerrada y comenzó la construcción de la escotadura del Zapote III (Arreguín-Cortés et al., 2014) para evitar la inundación que incomunicara a Villahermosa del aeropuerto y sureste del país. 
Figura 9. Identificación de zonas inundadas en el 2007 en la cuenca baja del río Grijalva

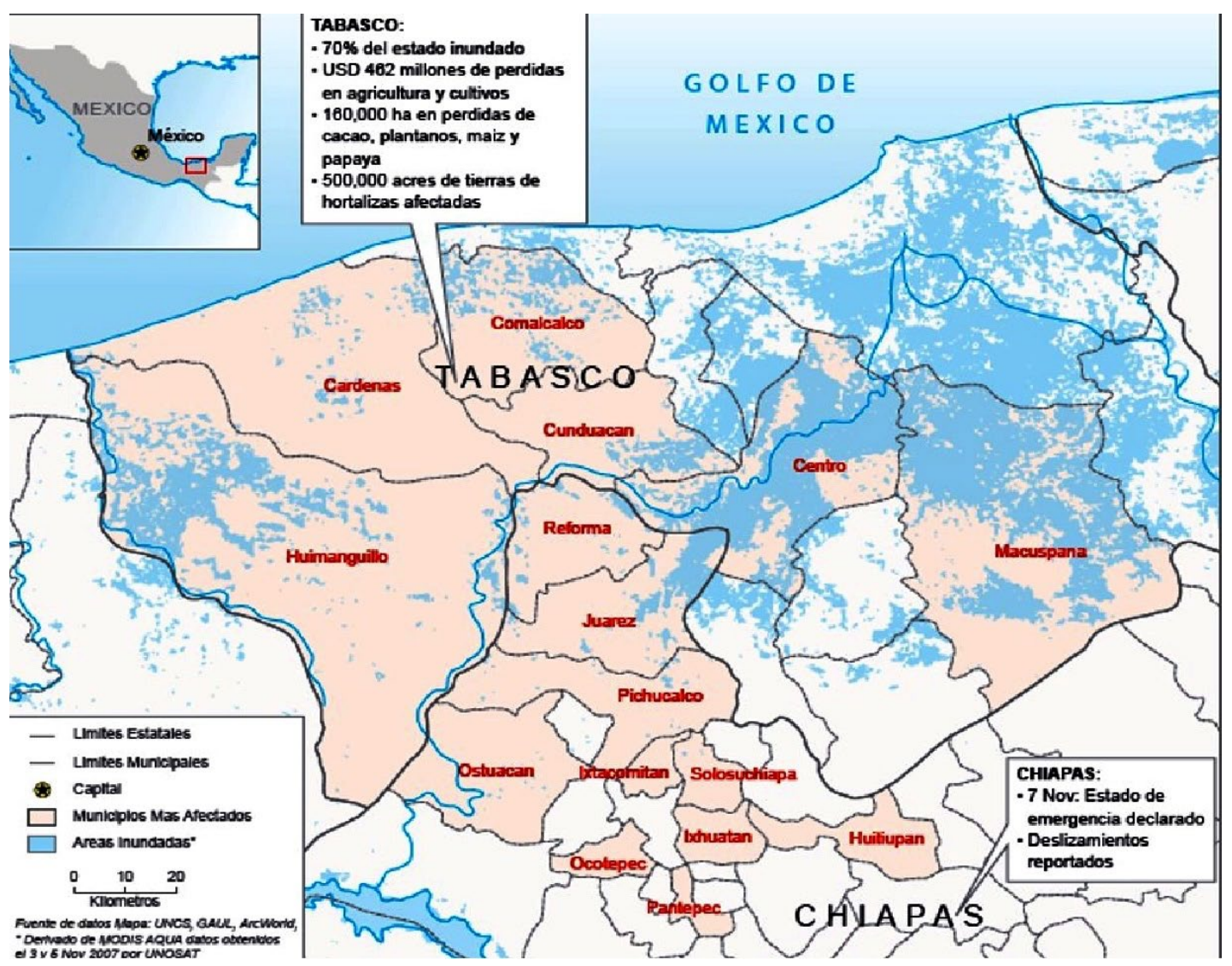

Fuente: RELIEFWEB, 2007. Elaboración propia.

\section{Conclusiones}

La interacción entre crecimiento urbano, actividades económicas predominantes y cambio de uso de suelo en la ciudad de Villahermosa permite distinguir dos periodos. El primero abarcó desde su fundación en el siglo XVI hasta mediados del siglo XX; mientras que el segundo se inició con la aplicación de programas de desarrollo económico y persiste hasta la fecha.

En el primer periodo, el crecimiento demográfico y urbano en Villahermosa fue limitado por los efectos de la piratería, y de las condiciones hidrometereológicas y climáticas, a los cuales se sumaron problemas de mortandad por epidemias, insalubridad y emigración por falta de incentivos económicos en comparación a provincias aledañas. Durante este período de bajo crecimiento urbano, las mayores transformaciones se restringieron principalmente a las derivaciones de los ríos que modificaron la red de drenaje superficial de los ríos de la cuenca baja del río Grijalva, las cuales provocaron la anegación de otras zonas y que Villahermosa fuera más vulnerable a las inundaciones, pues quedó rodeada de ríos. En forma similar a otras urbes latinoamericanas, las áreas no urbanizadas dentro de la ciudad y las suburbanas rurales fueron consideradas improductivas y propicias para sustituir su uso de suelo con actividades rentables. Sobre todo en Villahermosa y sus alrededores estas áreas estuvieron dominadas por lagunas con sus zonas de inundación temporal.

A mediados del siglo XX, el crecimiento urbano y la deforestación en el conjunto de la cuenca baja se incrementaron por la construcción del ferrocarril, carreteras y aplicación de programas de desarrollo económico. Éstos se fundamentaron en la construcción de presas en la cuenca media para controlar las inundaciones en la cuenca baja del río Grijalva y en sustituir las zonas de humedales y selváticas por zonas agropecuarias para abastecer de carne vacuna al país. Estos programas de desarrollo económico causaron efectos diferentes en la ciudad y en la cuenca baja. En la ciudad se saturó el espacio disponible dentro sus límites iniciales dado por los ríos que la rodean y a nivel de cuenca baja del Grijalva se modificaron 
los ciclos naturales de inundación y se deforestó la selva tropical. La saturación del espacio urbano, sumada a la petrolización de la economía, facilitaron la periurbanización, basada contradictoriamente en la protección de la ciudad contra las inundaciones, pero que permitió, como ha sucedido en Latinoamérica, la ocupación irregular de humedales conservados y mínimamente habitados, así como de zonas de bajo precio sin servicios municipales y poblados dedicados a la economía de subsistencia. En consecuencia, la población creció cinco veces más en las tres décadas posteriores al boom petrolero.

Figura 10. Obras hidráulica del Proyecto Integral Contra Inundaciones

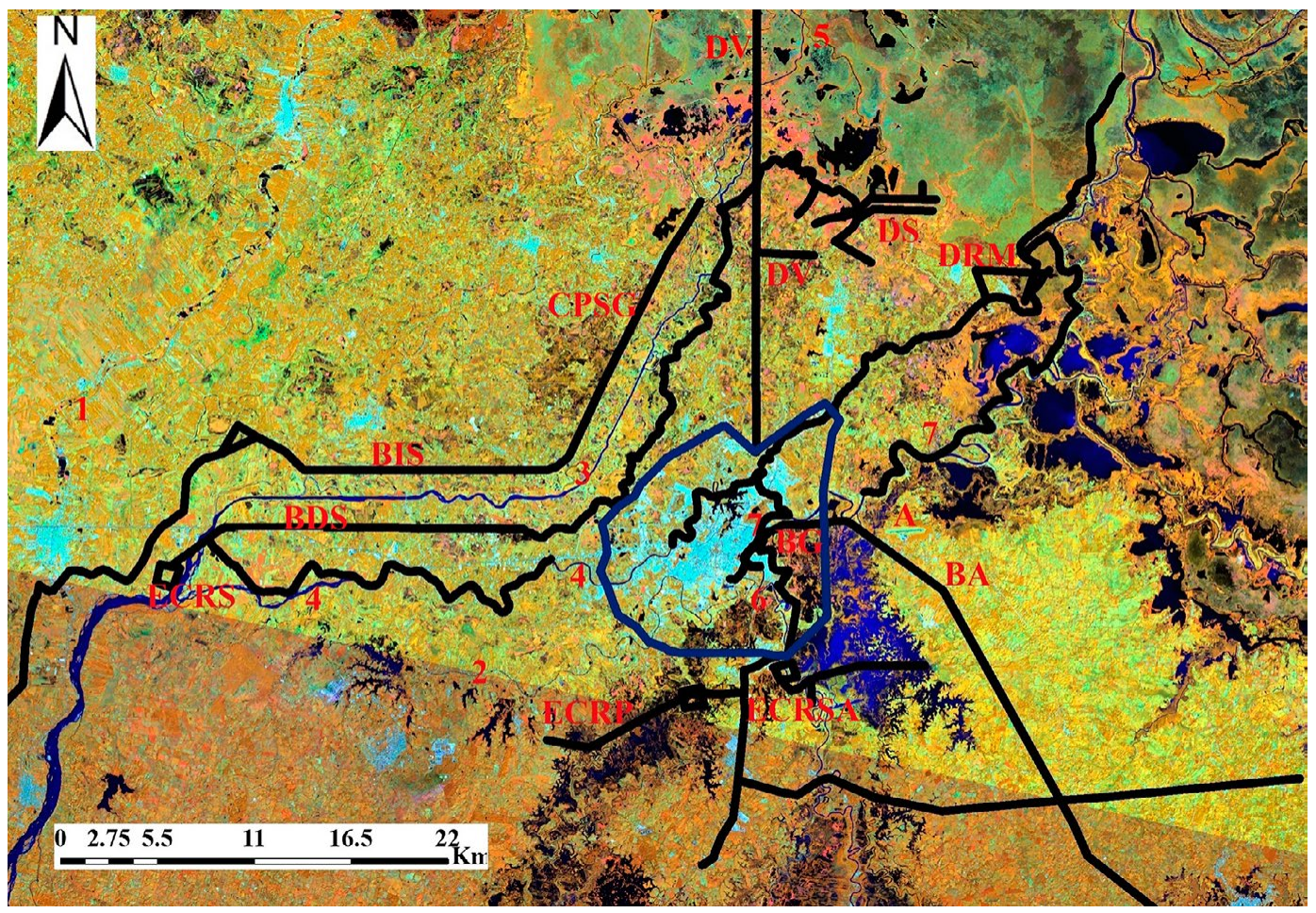

Nota: infraestructura del Proyecto Integral Contra Inundaciones: BIS=Bordo izquierdo Samaria, BDS=Bordo derecho Samaria, ECR$\mathrm{S}=$ Estructura de control río Samaria, BG=Bordo Gaviotas, DV=Dren Victoria, ECRP=Estación de control río Pichucalco, ECRSA=Estación de control río La Sierra, BA= Bordo aeropuerto, DS=Drenes hacia desagüe, DRM=Derivación del río Medellín, CPSG=Cause piloto Samaria - Gollo; ríos: 1= Seco, 2= Viejo Mezcalpa, 3= Samaria, 4= Carrizal, 5= González, 6=red fluvial aa Sierra y $7=$ Grijalva. Borde con línea azul=límite urbano de Villahermosa.

Fuente: Arreguín-Cortés et al., 2014. Elaboración propia.

La sustitución histórica de zonas arboladas y de humedales por zonas urbanas y periurbanas en Villahermosa persistió independientemente del periodo de crecimiento urbano. De forma similar, el desarrollo económico y la protección de la ciudad sobre las zonas suburbanas y rurales fueron objetivos prioritarios. Sin embargo durante el primer periodo (siglo XVI-mediados siglo XX), los efectos ambientales menos drásticos del crecimiento urbano se atribuyen al mínimo crecimiento demográfico y urbano; ya que durante los últimos 67 años (segundo periodo) la ciudad creció 7,1 veces. Bajo este modelo de periurbanización se perdieron 4.008 ha de vegetación arbórea y 289 ha de humedales en en sólo 16 años (1984 al 2008) y el área urbana aumentará dos veces del 2000 al 2030 con su consecuente pérdida de 2.795 y 460 ha de vegetación arbórea y humedales por continuar su fragmentación y aislamiento. La carencia y falta de actualización de manejo de aguas residuales y desechos sólidos en Villahermosa representa otra amenaza sobre la biodiversidad acuática de los humedales y la salud pública de los pobladores (Hansen et al., 2007; Sánchez et al., 2012). A estas alteraciones locales se agregaron la modificación de los ciclos naturales del flujo de agua y de los cauces de los ríos en la red hídrica de la cuenca baja del río Grijalva, que a su vez causaron el aislamiento hidráulico de los humedales urbanos, lo cual ha contribuido a agravar sus condiciones ecológicas. En este ámbito, el aumento en la intensidad y frecuencia de los eventos hidrometeorológicos asociados con el cambio climático global ha exacerbado la vulnerabilidad de la población y los efectos ambientales de la expansión urbana en la ciudad y en la cuenca. Como ejemplo, 
la vulnerabilidad en las inundaciones del 2007 y 2008 evidenció el resultado de la desaparición de los humedales por un inadecuado ordenamiento ecológico del territorio.

Adicionalmente, la transculturización de la sociedad, la omisión de la protección del patrimonio histórico, el cambio paulatino de sus percepciones y abandono de sus actividades productivas de subsistencia han sido favorecidas por la expansión urbana (Hettiarachchi et al., 2014; Pinkus-Rendón y Contreras-Sánchez, 2012; Salazar-Ledezma, 2000), que en Villahermosa también se vincula a los programas de desarrollo económico del siglo XX. En este contexto, la industrialización, los reglamentos de usos del suelo, la economía regional, los movimientos de población y el entorno político facilitan el control del cambio de uso de suelo al sector inmobiliario, para que los intereses y necesidades socioculturales queden en un segundo plano (Kolb, Mas y Galicia, 2013; Linard, Tatem y Gilbert, 2013). En el modelo insustentable de crecimiento urbano, la accesibilidad de la población dada por las vialidades también ha facilitado el establecimiento de nuevos centros de población en zonas marginadas o conservadas que demandan más infraestructura urbana (Gutiérrez, Condeço-Melhorado y Martín, 2010; Junliang, Xiaolu y Shoushuai, 2010; Kolb, Mas y Galicia, 2013) y ha propiciado que Villahermosa, al igual que otras ciudades latinoamericanas, haya evolucionado de ciudad compacta a urbe fragmentada (Bähr y Borsdorf, 2005).

Las tendencias de cambio de uso de suelo y deterioro ambiental en Villahermosa pueden ser mitigadas mediante el planeamiento basado en el diseño de un programa de regulación urbana incluyente, transdisciplinario, transparente y sustentable, que integre multi-escalas espaciales y temporales, respete el marco normativo, actualice las reservas territoriales, promueva la conservación y creación de áreas naturales protegidas e incluya el ordenamiento territorial en la cuenca del río Grijalva.

\section{Agradecimientos}

Al CONACyT por la beca otorgada al primer autor. Al Colegio de Posgraduados, Campus Montecillo por la capacitación sobre modelos geomáticos sobre el cambio de uso del suelo. Al Archivo Histórico del Estado de Tabasco por las facilidades prestadas.

\section{Referencias}

Allub, L. y Michel, M. A. (1979). La formación socioeconómica de Tabasco y el petróleo. Investigación Económica, 38 (148/149), 327-355. Recuperado de http://www.jstor.org/stable/42777039

Álvarez, G. D. C. y Tuñón, E. (2016). Vulnerabilidad social de la población desplazada ambiental por las inundaciones de 2007 en Tabasco (México). Cuadernos de Geografía-Revista Colombiana de Geografía, 25(1), 123-138. http://dx.doi.org/10.15446/rcdg.v25n1.52591

Angeoletto, F., Essy, C., Sanz, J. P. R., da Silva, F. F., Albertin, R. M. y Santos, J. W. M. (2015). Ecología Urbana: La Ciencia Interdisciplinaria del Planeta Ciudad. Desenvolvimento em Questão, 13(32), 6-20. https://doi.org/10.21527/2237-6453.2015.32.6-20

Arrieta, F. P. (1994). La integración social de la Chontalpa: un análisis regional en el trópico mexicano (Vol. 2). Ciudad de México: Universidad Iberoamericana, Gernika.

Arreguín-Cortés, F. I., Rubio-Gutiérrez, H., Domínguez-Mora, R. y Luna-Cruz, F. D. (2014). Análisis de las inundaciones en la planicie tabasqueña en el periodo 1995-2010. Tecnología y Ciencias del Agua, 5(3), 05-32. Recuperado de http://www.scielo.org.mx/pdf/tca/v5n3/v5n3al.pdf

Azócar, G., Sanhueza, R. y Henríquez, C. (2003). Cambio en los patrones de crecimiento en una ciudad intermedia: el caso de Chillán en Chile Central. EURE, 29(87), 79-82. https://doi.org/10.4067/S025071612003008700006

Bähr, J., y Borsdorf, A. (2005). La ciudad latinoamericana. La construcción de un modelo. Vigencia y perspectivas. Urbe. Revista de ciudad, urbanismo y paisaje (Lima), 2(2), 207-222. Recuperado de: http://www.guzlop-editoras.com/web_des/arquit01/pld0472.pdf

Bazant, J. (2010). Expansión urbana incontrolada y paradigmas de la planeación urbana. Espacio abierto. 19(3). Recuperado de http://200.74.222.178/index.php/espacio/article/view/1405

Bekessy, S. A., White, M., Gordon, A., Moilanen, A., Mccarthy, M. A. y Wintle, B. A. (2012). Transparent planning for biodiversity and development in the urban fringe. Landscape and Urban Planning, 108, 140-149. http://dx.doi.org/10.1016/j.landurbplan.2012.09.001 
Benítez, G., Pérez, A., Nava, M., Equihua, M. y Álvarez,J. L. (2012). Urban expansion and the environmental effects of informal settlements on the outskirts of Xalapa City, Veracruz, Mexico. Environment and Urbanization, 24(1), 149-166. https://doi.org/10.1177/0956247812437520

Capdepont-Ballina, J. L. y Marín-Olán, P. (2014). La economía de Tabasco y su impacto en el crecimiento urbano de la ciudad de Villahermosa (1960-2010). LiminaR, 12(1), 144-160. Recuperado de http:// liminar.cesmeca.mx/index.php/r1/article/view/330/310

Carranza, J. E. y Ruiz, N. (2012). Urbanización invasiva en el crecimiento de la ciudad de Puebla México. Revista ASUNTOS, 1(22), 121-120. Recuperado de https://www.researchgate.net/profile/Martha Ortiz3/publication/277587957_Modelo_de_desarrollo_y_derechos_humanos_con_perspectiva_de gnero/links/556dd49308aec2268308bc21.pdf\#page=121

Cerna, G. S. G, de la Peña, M. R., Antonio, G. G. y Reyna y Díaz, C. A. J. (2011). Tabasco y sus Asentamientos Humanos, Dos Siglos Después. Villahermosa: Secretaría de Asentamientos y Obras Públicas.

Chávez-Jiménez, U. (2007). Potonchán y Santa María de la Victoria. Una propuesta geomorfológico/ arqueológica a un problema histórico. Estudios de Cultura Maya, 29. Recuperado de http://revistas. unam.mx/index.php/ecm/article/view/36194

Comisión Económica para América Latina [CEPAL] (2008). Tabasco: Características e Impacto Socioeconómico de las Inundaciones Provocadas a Finales de Octubre y a Comienzos de Noviembre de 2007 por el Frente Frio Número 4. Recuperado de http://www.cepal.org/publicaciones/xml/3/33373/ L864_parte_1_de_8.pdf

Comisión Económica para América Latina [CEPAL] (2011). Tabasco:Característicaseimpactosocioeconómico de las lluvias extremas de 2008. Recuperado de http://www.cepal.org/es/publicaciones/26048-tabascocaracteristicas-impacto-socioeconomico-lluvias-extremas-2008.

Comisión Nacional del Agua [CONAGUA] (2011). Identificación de reservas potenciales de agua para el medio ambiente en México. Recuperado de http://www.conagua.gob.mx/CONAGUA07/Publicaciones/ Publicaciones/SGT-3-11Media.pdf

Consejo Nacional de Población [CONAPO] (2006). La situación demográfica en México. 2006. Recuperado de http://www.conapo.gob.mx/es/CONAPO/La_situacion_demografica_de_Mexico_2006

da Silva, C. J. y Cardozo, O. D. (2015). Evaluación Multicriterio y Sistemas de Información Geográfica aplicados a la definición de espacios potenciales para uso del suelo residencial en Resistencia (Argentina). Geofocus: Revista Internacional de Ciencia y Tecnología de la Información Geográfica, (16), 2 Recuperado de http://www.geofocus.org/index.php/geofocus/article/view/445/331

Díaz-Perera, M. Á. (2014). La construcción histórica de las condiciones de posibilidad de un desastre: el caso de dos colonias de Villahermosa, Tabasco. En M. González-Espinosa, y M. C. Brunel-Manse (Eds.), Montañas, pueblos y agua: dimensiones y realidades de la cuenca Grijalva (pp. 1-25). Ciudad de México: Editorial Juan Pablos. Recuperado de http://cuencagrijalva.ecosur.mx/cuenca_grijalva/files/ informe_Final/sp03_archivos/03_0709_cap_7_construccion_condiciones_historicas.pdf

Eastman, J. R. (2012). IDRISI Selva GIS and image processing software version 17.0. Massachusetts, USA: Clark Labs.

Flores-Santiago, A. (1987). La modernización de la agricultura en el trópico húmedo mexicano: veinte años de experiencia en la Chontalpa, Tabasco. Revista de Geografía Agrícola, 13-14(2): 105-114 Recuperado de http://www.chapingo.mx/revistas/geografia/contenido.php?id_articulo=1735?id_ revistas $=4$ ? id_revista_numero $=174$

Garza, G. (2010). La transformación urbana de México, 1970-2020. En G. Garza y M. Schteingart (Eds.), Los grandes problemas de México. Desarrollo urbano y regional. (pp. 31-86). Ciudad de México: El Colegio de México AC. Recuperado de http://2010.colmex.mx/16tomos/II.pdf

Gracia, J. y Fuentes, O. (2004). La problemática del agua en Tabasco: Inundaciones y su control. En B. Jiménez y L. Marín (Eds.), El agua en México vista desde la academia (pp. 177-185) Ciudad de México: Academia Mexicana de Ciencias.

Gurría-Lacroix, J., Castel, M. y Guzmán, R. (1982). Atlas histórico de Tabasco. 1570-1981. Villahermosa: Consejo Editorial del Estado de Tabasco. 
Gutiérrez, J., Condeço-Melhorado, A. y Martín, J. C. (2010). Using accessibility indicators and GIS to assess spatial spillovers of transport infrastructure investment. Journal of Transport Geography, 18(1), 141-152. https://doi.org/10.1016/j.jtrangeo.2008.12.003

Gutman, P. (1993). La Habana y Seúl: ejemplos de metropolización. EURE. Revista Latinoamericana de Estudios Urbano Regionales, 19(57), 103-115. Recuperado de http://www.eure.cl/index.php/eure/ article/view/1108

Hansen, A. M., van Afferden, M. y Torres, F. (2007). Saneamiento del vaso Cencali, Villahermosa, Tabasco. I. Contaminación y reúso de sedimentos. Ingeniería Hidráulica en México, XXII (4), 87-102. Recuperado de http://repositorio.imta.mx:8080/cencarepositorio/bitstream/123456789/847/1/215 854.pdf

Henny, C. y Meutia, A. A. (2014). Urban Lakes in Megacity Jakarta: Risk and Management Plan for Future Sustainability. Procedia Environmental Sciences, 20, 737-746. https://doi.org/10.1016/j. proenv.2014.03.088

Heroico Ayuntamiento del Municipio de Centro 2016-2018 (2016). Plan Municipal de Desarrollo 2016 - 2018, Centro-Tabasco. Recuperado de http://oficial.villahermosa.gob.mx/ villahermosagob/images/ documentos_pdf/plan_municipal.pdf

Hettiarachchi, M., Morrison, T. H., Wickramsinghe, D., Mapa, R., De Alwis, A. y McAlpine, C. A. (2014). The eco-social transformation of urban wetlands: A case study of Colombo, Sri Lanka. Landscape and Urban Planning, 132, 55-68. http://dx.doi.org/10.1016/j.landurbplan.2014.08.006

Hernández, H. M. M. (2011). Inundación, reubicación y cotidianidad. El caso de Villahermosa, Tabasco, 2007. Tesis de Maestría. Centro de Investigaciones y Estudios Superiores en Antropología Social, Unidad Golfo, 133 pp., Xalapa, México. Recuperado de http://docencia.ciesas.edu.mx/Tesis/PDF/488.pdf

Ibarra, V., Puente, S. y Schteingart, M. (1984). La ciudad y el medio ambiente. Demografía y economía, 18(1), 110-143. https://doi.org/10.24201/edu.v18i01.1603

Instituto Nacional de Estadística y Geografía [INEGI] (2000). Sistema Ciudades Capitales: Una visión histórico urbana. Recuperado de http://www.inegi.org.mx/geo/contenidos/urbana/ciud_cap.aspx

Instituto de Planeación y Desarrollo Urbano del Municipio de Centro [IMPLAN] (2008). Programa de Desarrollo Urbano del Centro de Población de la Ciudad de Villahermosa y Centros Metropolitanos del Municipio de Centro, Tabasco 2008-2030. Villahermosa: H. Ayuntamiento Constitucional de Centro. Recuperado de http://www.ordenjuridico.gob.mx/fichaOrdenamiento.php?idArchivo=26617\&ambito=

Izquierdo, A. L. y Bustos, G. (1984). La visión geográfica de la Chontalpa en el siglo XVI. Estudios de Cultura Maya, 15: 143-177. Recuperado de https://revistas-filologicas.unam.mx/estudios-culturamaya/index.php/ecm/article/view/569

Junliang, D., Xiaolu, G. y Shoushuai, D. (2010). Expansion of Urban Space and Land Use Control in the Process of Urbanization: An Overview. Chinese Journal of Population Resources and Environment, 8(3), 73-82. https://doi.org/10.1080/10042857.2010.10684994

Kolb, M. y Galicia, L. (2012). Challenging the linear forestation narrative in the Neo-tropic: regional patterns and processes of deforestation and regeneration in southern Mexico. The Geographical Journal, 178 (2), 147-161. https://doi.org/10.1111/j.1475-4959.2011.00431.x

Landgrave, R. y Moreno-Casasola, P. (2012). Evaluación cuantitativa de la pérdida de humedales en México. Investigación ambiental, 4(1), 19-35. Recuperado de http://www2.inecc.gob.mx/publicaciones/ gacetas/663/humedales.pdf

Lezama, J. L. (1987). Migración y petróleo en Tabasco. Estudios Demográficos y Urbanos, 231-256. https:// doi.org/10.24201/edu.v2i2.627

Linard, C., Tatem, A. J. y Gilbert, M. (2013). Modelling spatial patterns of urban growth in Africa. Applied Geography, 44, 23-32. https://doi.org/10.1016/j.apgeog.2013.07.009

Maltby, E. y Acreman, M. C. (2011). Ecosystem services of wetlands: pathfinder for a new paradigm. Hydrological Sciences Journal, 56, 1341-1359. https://doi.org/10.1080/02626667.2011.631014

Merlín-Uribe, Y., Contreras-Hernández, A., Astier-Calderón, M., Jensen, O. P., Zaragoza, R. y Zambrano, L. (2013). Urban expansion into a protected natural area in Mexico City: alternative management scenarios. Journal of Environmental Planning and Management, 56(3), 398-411. https://doi.org/10.108 $\underline{0 / 09640568.2012 .683686}$ 
Miller, R. R., Minckley, W. L. y Norris, S. T. (2005). Freshwater fishes of Mexico. Chicago: The University of Chicago Press.

Moreno-Amador, C. M. (2014). La población en la provincia de Tabasco durante el periodo colonial (siglos XVI-XVII): un estudio revisionista. Naveg@mérica, (13). Recuperado de http://revistas.um.es/ navegamerica/article/view/208481/166741

Moreno-Casasola, P. (2008). Los humedales en México: tendencias y oportunidades. Cuadernos de biodiversidad, (28), 10-18. https://doi.org/10.14198/cdbio.2008.28.02

Murillo, L. D. (2004). Falacias del desarrollo sustentable: una crítica desde la metamorfosis conceptual. Revista Economía, Sociedad y Territorio, 4(16). https://doi.org/10.22136/est002004406

Murillo, L. D. y Martínez, R. J. (2010). Comunicación para el desarrollo en México: reflexiones sobre una experiencia en el trópico húmedo. Estudios sobre las culturas contemporáneas, (31), 201225. Recuperado de http://www.culturascontemporaneas.com/contenidos/8\%20Testimonio\%20 Murillo\%20pp\%20201-225.pdf

Navarro, J. M. y Toledo, H. (2008). Transformación de la cuenca del río Grijalva, Revista Noticias AMIP, 4(16), 11-22. Recuperado de http://www.amip.org.mx/htm/RevAMIP/A4NUM16/

Orellana, A., Arenas, F, Marshall, C. y Rivera, A. (2016). Resistance to metropolitan institutionality and planning in Chile. Planning Practice and Research, (31), 435-451. https://doi.org/10.1080/02697459. $\underline{2016.1196535}$

Organización de las Naciones Unidas para la Alimentación y la Agricultura [FAO] (2015). Evaluación de los recursos forestales mundiales 2015. Recuperado de http://www.fao.org/3/a-i4808s.pdf

Palacio-Prieto, J. L., Sánchez-Salazar, M. T., Casado, J. M., Propin, F. E., Delgado, C. J., Velázquez, M. A. y Camacho, R. C. G. (2004). Indicadores para la caracterización y el ordenamiento territorial. México: SEMARNAT. Recuperado de http://www2.inecc.gob.mx/publicaciones/download/434.pdf

Perevochtchikova, M. y Lezama, T. J. L. (2010). Causas de un desastre: Inundaciones del 2007 en Tabasco, México. Journal of Latin American Geography, 9(2), 73-98. https://doi.org/10.1353/lag.2010.0010

Pinkus-Rendón, M. J. y Contreras-Sánchez, A. (2012). Impacto socioambiental de la industria petrolera en Tabasco: el caso de la Chontalpa. LiminaR, 10(2), 122-144. Recuperado de http://liminar.cesmeca. $\underline{\mathrm{mx} / \mathrm{index} . \mathrm{php} / \mathrm{rl} / \mathrm{article} / \mathrm{view} / 99 / 86}$

RELIEFWEB (2007). México: Inundaciones de Tabasco y Chiapas. Recuperado de: http://reliefweb.int/map/ mexico/mexico-inundaciones-de-tabasco-y-chiapas-al-9-de-nov-2007

Rosete-Vergés, F. A., Pérez, J. L., Villalobos, M., Navarro, E. N., Salinas, E. y Remond, R. (2014). El avance de la deforestación en México 1976-2007. Madera y bosques, 20(1), 21-35. https://doi.org/10.21829/ $\underline{\text { myb.2014.201173 }}$

Ruiz-Abreu, C. E. (2002). Rutas, impuestos y productos comerciales de Tabasco en el siglo XVIII. Boletín Oficial del INAH Antropología, (66), 41-52. Recuperado de https://revistas.inah.gob.mx/index.php/ antropologia/article/view/4990/5016

Ruz, M. H. (2002). De piratas e historias en el Tabasco colonial. Boletín Oficial del INAH Antropología, (66), 2-19 Recuperado de https://revistas.inah.gob.mx/index.php/antropologia/article/view/4987

Salazar-Ledesma, F. (2000). Factores de destrucción del patrimonio histórico urbano. Ciudad de Villahermosa. NayA. Recuperado de http://www.equiponaya.com.ar/congreso2000/ponencias/Flora Salazar.htm.

Salazar-Ledesma, F. (2002). Ubicación cartográfica de Villahermosa en 1579. Boletín Oficial del INAH Antropología, (66), 32-40. Recuperado de https://revistas.inah.gob.mx/index.php/antropologia/article/ view/4989/5015

Salazar-Ledesma, F. (2008). De señor a tributario: Historia breve del gran Mazapa. Península, 3(1), 11-34. Recuperado de http://www.revistas.unam.mx/index.php/peninsula/article/view/44349

Sánchez, A. J., Salcedo, M. A., Macossay, A., Feria, Y., Vázquez, L., Ovando, N. y Rosado, L. (2012). Calidad ambiental de la laguna urbana la Pólvora en la cuenca del río Grijalva. Revista Tecnología y Ciencias del Agua, 3(3), 143-152. Recuperado de: http://www.scielo.org.mx/pdf/tca/v3n3/v3n3al0.pdf 
Sánchez, A. J., Salcedo, M .A., Florido, R., Mendoza, J. D., Ruiz-Carrera, V. y Álvarez-Pliego, N. (2015). Ciclos de inundación y conservación de servicios ambientales en la cuenca baja de los ríos GrijalvaUsumacinta. ContactoS, 97, 5-14. Recuperado de http://www.izt.uam.mx/newpage/contactos/index. php/es/

Sánchez-Munguía, A. (2005). Uso del suelo agropecuario y deforestación en Tabasco 1950-2000. Villahermosa: Universidad Juárez Autónoma de Tabasco.

Sánchez-Salazar, M. (1990). La industria petrolera como factor de cambios territoriales en la economía nacional, a partir de los años setenta. Investigaciones Geográficas, (21), 75-95. Recuperado de http:// www.scielo.org.mx/pdf/igeo/n21/n21a5.pdf

Schteingart, M. (1987). Expansión urbana, conflictos sociales y deterioro ambiental en la ciudad de México. El caso del Ajusco. Estudios demográficos y urbanos, 449-477. https://doi.org/10.24201/edu. $\underline{\mathrm{v} 2 \mathrm{i} 3.650}$

Toledo, A. A., Vázquez-Botello, A. y Herzig, M. (1987). El pantano: una riqueza que se destruye. Serie Medio Ambiente en Coatzacoalcos (vol 7). Ciudad de México: Centro de Ecodesarrollo. Recuperado de http://cdigital.uv.mx/bitstream/123456789/4975/2/mac12pan.pdf

Torruco, G. (2014). Tabasco Recuento histórico. En M. de la Cruz, T. de la Cruz, V. Gatti (Eds.), Tabasco. El edén de México. (pp. 39-69). Índice Editores Fons S.A. de C.V.

Zavala, J. y Castillo, A. O. (2007). Cambio de uso de la tierra en el estado de Tabasco. En D. J. Palma y A. Triano (Eds.), Plan de uso sustentable de los suelos del estado de Tabasco (vol, II, pp. 38-56). Villahermosa: Colegio de Posgraduados. Recuperado de https://www.researchgate.net/publication/293958386_Plan de uso sustentable de los suelos de Tabasco_Vol_II

Zavala, J., Castillo, A. O., Ortiz, I. C., Palma, D. J., Salgado, G. S., Rincón, R. J. A., y Ramos, R. R. (2009). Capacidad de uso del suelo urbano en Tabasco: Con base en suelo, uso actual y vegetación. Cárdenas: Colegio de Posgraduados. 